\title{
Wind Loading on Attached Canopies: A Codification Study
}

José D. Candelario, S.M.ASCE${ }^{1}$; Ted Stathopoulos, F.ASCE²; Ioannis Zisis, M.ASCE ${ }^{3}$

\begin{abstract}
A wind tunnel study has been performed to examine wind loads on canopies attached to the walls of low-rise buildings. A building with an attached canopy model of a geometric scale of 1:100 was constructed and tested in a simulated open terrain exposure. The attached canopy model was equipped with pressure taps at both upper and lower surfaces to allow for the simultaneous monitoring of wind pressures and the evaluation of the overall load. A total of 63 different building/attached canopy configurations were tested for 28 wind directions. Pressure and correlation coefficients have been generated to provide a better understanding of how the wind-loading patterns at upper and lower surfaces of the attached canopy contribute to the net loading effect. Current design guidelines and building code and standard provisions are assessed and compared with the experimental results of the present study. The influence of the geometry of each configuration on the experimental net pressure coefficients has been assessed and recommendations for design wind load standards and codes of practice are made.
\end{abstract}

${ }^{1}$ Graduate Student, Dept. of Building, Civil and Environmental Engineering, Centre for Building Studies, Concordia University, Montreal QC, Canada H3G 1M8 (corresponding author).

${ }^{2}$ Professor, Dept. of Building, Civil and Environmental Engineering, Centre for Building Studies, Concordia University, Montreal QC, Canada H3G 1M8.

${ }^{3}$ At present, Assistant Professor, Dept. of Civil and Environmental Engineering, Florida International University, Miami, FL 33174. 


\section{INTRODUCTION}

An attached canopy is a roof adjacent to the wall of a building. This kind of addition is of common use in suburban low-rise housing because it provides a space adequate for many social and leisure activities with partial protection from the elements. The wall to which the canopy is attached is referred to as the parent wall and it also represents the only enclosed side of the canopy.

Currently there is only limited knowledge in terms of what the design loads should be for these types of structures. Neither the National Building Code of Canada 2010 (NBCC), nor the American Society of Civil Engineers Standard (ASCE 7-10) have any wind load provisions for the proper design of attached canopies. In North America, only the International Building Code (IBC 2006) and the International Residential Code (IRC 2006) contain some provisions to address this issue. However, these provisions do not seem to result from a detailed study.

Due to this lack of design provisions in the North American codes and standards, designers and practitioners have found ways to obtain approximate design loads by use of the aforementioned codes. One such example is to treat the attached canopy as though it were an extension of the roof overhang, and design it according to the provisions available in the ASCE 7-10 or NBCC.

The purpose of this paper is to present the methodology used and experimental findings obtained from a series of wind tunnel measurements on a building model with an instrumented attached canopy. A commentary on comparisons with available international studies and design guidelines is provided as well as recommendations for design guidelines for possible implementation in future standards and codes of practice. 
This study extends significantly the results of a previous pilot study (Zisis and Stathopoulos, 2010) also undertaken in the Building Aerodynamics Laboratory at Concordia University but addressing only a very limited number of cases.

\section{Previous Studies and Design Provisions}

Previous studies of wind loads on attached canopies provided a foundation for the development of the present study. Parameters, procedures and findings, as well as the inconsistencies presented amongst each other, were carefully investigated before defining the test program of the present study.

One of the first studies dealing with wind loads on attached canopies is that of Jancauskas and Holmes (1985). Experiments were performed in a boundary layer wind tunnel for a roughness simulating an urban terrain exposure. A total number of 14 configurations were tested in this study by varying the height of the building, the height at which the canopy is placed, the length of the canopy, and its width. This study forms the basis of the provisions available on the AS/NZS 1170.2:2002.

Paluch et al. (2003) carried out extensive work regarding wind loads on canopies attached to buildings with arched roof. Pressure coefficients presented in this paper however, consider loads applied on the upper and lower surfaces of the canopy separately and not their net effects. It must be added that a greater focus is given to the loads acting on the roof as a result of the presence of a canopy than to the loads on the canopy itself.

Hölscher et al. (2007) performed an extensive study on wind-induced pressures on canopies attached to the walls of flat roof buildings. Experiments were carried out in a boundary layer 
wind tunnel both with and without surroundings. For each configuration, 24 wind directions were tested. Both local and area-averaged peak loads have been analyzed. The results form the basis of the design guidelines provided in Eurocode 1 for Wind Actions (DIN EN 1991-1$4: 2010-12)$

Zisis and Stathopoulos (2010) carried out a detailed study on wind-induced pressures on attached canopies. The experiments were performed in a boundary layer wind tunnel for a roughness simulating an open terrain exposure. The loads were determined using a system of pressure sensitive scanners. For each configuration a total of 28 wind directions were tested. This study presents both local and area-averaged peak loads, as well as pressure and correlation coefficient contour plots so as to give a better understanding of the loading patterns on attached canopies. Three different configurations were tested for an attached canopy extending over the entire length of the parent wall.

In addition to the AZ/NZS 1170.2:2002 and the DIN EN 1991-1-4/NA:2010-12, provisions for the wind load design of attached canopies are also available on the Austrian Standard (ÖNORM B 4014-1), the Swiss Standard (Schweizerische Norm, SIA 261), and the Indian Standard code of practice for design loads (IS: 875 Part-3-1987). Two main geometric parameters are present in most of these design provisions and are commonly considered to have the greatest impact on wind loads; the hc/h ratio (height of canopy to eave height) and the hc/wc ratio (height of canopy to width of canopy). Additional parameters have also been considered, but their effect has been deemed to be less significant.

In order to provide a quick comparison, three different canopy and parent building geometries were selected and designed in accordance with the five available design guidelines. Figure 1 
presents the maximum (uplifting; -) and minimum (downwards; +) net pressure coefficients obtained from each geometry. These coefficients have been normalized by the dynamic velocity pressure based on the 3-sec gust. The inconsistencies that arise depending on design guidelines followed can be clearly noted. Design uplifting pressure coefficients can vary by up to a $70 \%$ difference for canopies located near the eave height. Furthermore, a zero value was obtained in one of the cases for a canopy attached at a lower relative height. These discrepancies served as a motivation and demonstrated the pertinence of the present study.

\section{WIND TUNNEL STUDY}

Experimentation for the present study was performed in the Boundary Layer Wind Tunnel (BLWT) at Concordia University's Building Aerodynamics Laboratory. An acrylic glass model with a scale of 1:100 serves as the parent building to which a metallic canopy model of the same geometric scale is to be attached. The building model has external dimensions of $15 \mathrm{~cm}$ by $10 \mathrm{~cm}$ (length-width) and a ridge height of $12.30 \mathrm{~cm}$ as shown in Figure 2. The gabled roof has a slope of $4: 12$. The parent wall of the building model consists of five wall segments of unique widths which may be arranged in different ways so as to provide a slot at different positions to which the canopy model can be attached (see Fig. 3). In addition, the height of the building model can be lowered by the use of an adjustable base.

Two separate canopy models have been made out of thin sandwiched metallic plates. One of the models stretches the entire length of the parent wall $(15 \mathrm{~cm})$ whereas the other stretches over half of the length $(7.5 \mathrm{~cm})$. Both models have the same width of $3.65 \mathrm{~cm}$, which can be further reduced by pushing it deeper into the slot of the building model. Pressure taps have been placed at both upper and lower surfaces of the canopy at almost the same locations in order to form 
pressure tap pairs which enable the determination of net pressure coefficients. Pressure tap locations for both models are shown in Figure 4. The full-length canopy model has a total of 30 pressure taps (15 pressure tap pairs) and the half-length canopy model has a total of 18 pressure taps (9 pressure tap pairs).

To refer to the relevant parameters the nomenclature illustrated in Figure 5 has been followed during the course of this study. The eave height $(h)$ and the wall length $(l)$ refer to the dimensions of the parent building, whereas the canopy height $\left(h_{c}\right)$, canopy width $\left(w_{c}\right)$, and canopy length $\left(l_{c}\right)$ describe the geometry and location of the attached canopies. The canopy edge to building edge distance $\left(e_{d}\right)$ accounts for the horizontal location of the attached canopy. The adjustable model results in the possibility of testing 63 configurations, i.e. each of the three cases (Case I, II and III) shown in Fig. 5 tested for the 21 configurations described in Table 1.

The dimensionless ratios in Table 1 were selected to cover geometries commonly found in practice, in combination with other less common configurations. As a result, more comprehensive design guidelines can be obtained and the trends and effects of the relative geometries can be better assessed. The following are the four ratios tested as principal variables in this study with their corresponding ranges in brackets:

$$
\begin{aligned}
& >\frac{h c}{h}=\{0.20 \text { to } 0.94\} \\
& >\frac{h c}{w c}=\{0.58 \text { to } 8.54\} \\
& >\frac{l c}{l}=\{0.5 \text { to } 1\} \\
& >\frac{e d}{l c}=\{0 \text { to } 1\}
\end{aligned}
$$


Please note that Table 1 also indicates with a star the three configurations tested previously for Case I (Zisis and Stathopoulos, 2010), the results of which were used for repeatability checks.

The experiments were performed for a simulated open terrain exposure. The average and root mean square longitudinal wind velocities $(\bar{V} z$ and $V z, r m s)$ were measured at different heights at the center of the wind tunnel test section without the model in place. The corresponding average velocity $(\bar{V} z)$ and longitudinal turbulence intensity $(V z, r m s / \bar{V} z)$ profiles are shown in Figure 6. Plotting the power law with an exponent of $\alpha=0.14$ results in the best agreement with the measured values. The experimental turbulence intensity profile also portrays consistency with the analytical curve derived from the logarithmic law as:

$I_{(z)}=\frac{2.5 v_{*}}{\frac{v_{*}}{0.4} \ln \left(\frac{z}{z_{O}}\right)}=\frac{1}{\ln \left(\frac{z}{z_{o}}\right)}$

where $z$ is the height above the surface, $z_{o}$ is defined as the roughness length, found to be $0.01 \mathrm{~cm}$ for an open terrain exposure, and $v_{*}$ is the shear velocity.

The turbulence intensities at the mean roof height $(\mathrm{mrh})$ for the three different parent building heights tested were found to be $17.9 \%(\mathrm{mrh}=4.5 \mathrm{~cm}), 15.5 \%(\mathrm{mrh}=8 \mathrm{~cm})$, and $14.4 \%(\mathrm{mrh}=$ $11.3 \mathrm{~cm}$ ) thus complying with the importance of proper simulation of the turbulence intensity when dealing with low-rise buildings (Tieleman et al. 1998).

The equipment used for the flow visualization consisted of a Dantec smoke generator and highspeed video equipment. The instrumentation used for the measurement of the wind flow characteristics was a TFI Cobra multi-hole probe with a frequency response exceeding $2000 \mathrm{~Hz}$ suitable for both turbulent and mean flow measurements. Pressure taps placed on the model are connected by urethane tubing to a pressure sensitive scanner (ZOC33/64 Px-2003, Scanivalve 
Corp.) which is in turn connected to the data acquisition system (DSM 3000, Scanivalve Corp.). A Pitot tube was placed at the free flow above the boundary layer and was connected to the scanning system to measure the dynamic and static pressure. The system was set to operate at a scanning frequency of $250 \mathrm{~Hz}$ generating 8200 pressure readings in approximately $32 \mathrm{~s}$. These values simulate the wind flow characteristics of a full-scale storm event one-hour long. As a result, the data presented in this study correspond to hourly wind speed data unless stated otherwise. A total number of 28 wind directions were examined for each of the 63 configurations tested. The step size of wind directions ranges from $5^{\circ}$ in critical ranges to $25^{\circ}$ in ranges where critical pressures are less likely to occur.

All data acquired by the pressure scanner is presented in dimensionless pressure coefficient form in accordance with the following equation:

$$
C p=\frac{\Delta P}{q_{m r h}}=\frac{P_{t}-P_{a}}{q_{m r h}}
$$

where $P_{t}=$ surface pressure at any tap; $P_{a}=$ atmospheric pressure; $q_{m r h}=$ dynamic velocity pressure at mean roof height converted from $q_{\text {pitot }}$ by use of the power law velocity profile as follows:

$q_{m r h}=q_{p i t o t}\left(\left(\frac{z_{m r h}}{z_{g}}\right)^{\alpha}\right)^{2}$ 
Since the canopy is generally a thin element exposed to wind pressures on both upper and lower surfaces it is essential to consider the pressures acting simultaneously on each plane. This is done by the use of net pressure coefficients as defined in the following equation:

$C p_{\text {,net }}=\frac{\Delta P_{\text {, net }}}{q_{\text {mrh }}}=\frac{\Delta P_{\text {,upper }}-\Delta P_{\text {,lower }}}{q_{m r h}}=C_{p, \text { upper }}-C_{p, \text { lower }}$

in which $\Delta P_{\text {,upper }}$ and $\Delta P_{\text {,lower }}$ are measured at top and bottom components respectively of a pressure tap pair as illustrated in Figure 7. It must be noted that the negative sign represents a pressure directed away from the surface (suction) and a positive sign represents a pressure directed towards a surface. If this convention is maintained when computing net loads in accordance with equation (3) a negative value for a $C p$,net will result in a net uplifting load, whereas a positive value will result in a net downward loading.

Throughout this paper peak pressure coefficients may be identified as either local or areaaveraged. A local peak $C p$ refers to the critical value experienced at a single pressure tap (or pressure tap pair in the case of local $C p_{\text {,net }}$ ). An area-averaged $C p$ refers to the peak value that the entire area experiences determined by the average of pressures measured at every pressure tap (or pressure tap pair) simultaneously. Both local and area-averaged pressure coefficients are referred to as minimum, maximum or mean, defined as follows:

$C_{p, \text { minimum }}=\frac{\left(\widetilde{P_{t}}-P_{a}\right)}{q_{m r h}}$ 
$C_{p, \text { maximum }}=\frac{\left(\widehat{P_{t}}-P_{a}\right)}{q_{m r h}}$

$$
C_{p, \text { mean }}=\frac{\left(\overline{P_{t}}-P_{a}\right)}{q_{m r h}}
$$

where $\breve{P}_{t}, \widehat{P}_{t}$, and $\bar{P}_{t}$ are the extreme minimum, extreme maximum, and mean pressure recorded during the simulated storm. In the case of individual surface pressures (at one pressure tap) the minimum peak is associated with the highest suction, whereas the maximum peak is associated with the highest positive pressure. In the case of net pressures the minimum peak is associated with the highest net uplifting load, and the maximum peak is associated with the highest downward loading.

\section{RESULTS AND DISCUSSION}

\section{Effect of wind direction on local net pressure coefficients}

Pressure coefficients on attached canopies may vary significantly with wind direction. Figures 8 and 9 display the local maximum, minimum and mean $C p_{\text {,net }}$ values as a function of wind direction for two different configurations. Given that the highest local $C p_{\text {, net }}$ value may occur at a different location of the canopy for different wind directions, the local net pressure coefficients presented in Figures 8 and 9 correspond to the highest value found at any pressure tap pair throughout the entire canopy for each particular wind direction. 
For a canopy extending over the entire length of the parent wall as shown in Figure 8 it can be seen that the highest magnitudes for local peak minimum $C p_{\text {,net }}$ values occur at the $330^{\circ}$ wind direction. The highest local peak maximum $C p_{\text {, net }}$ occurs at the $225^{\circ}\left(135^{\circ}\right)$ wind direction. In addition, the lowest magnitudes for both local maximum and minimum $C p_{\text {, net }}$ values were found to occur when the canopy is placed at the leeward wall $\left(180^{\circ}\right)$. It must be noted that local peak $C p_{\text {,net }}$ values display a great sensitivity to wind direction. In the configuration examined, the local peak minimum $C p_{\text {,net }}$ obtained at $330^{\circ}$ degrees is about five times that encountered at $180^{\circ}$.

In the case presented in Figure 9 for a canopy extending half the length of the parent wall and placed eccentrically along the length of the parent wall, a very different behavior is observed. The highest magnitude local peak minimum $C p_{\text {, net }}$ values are found to occur for wind directions running parallel to the building ridge $90^{\circ}-270^{\circ}$ and the highest local peak maximum $C p_{\text {,net }}$ values occur at wind directions nearly perpendicular to the ridge $15^{\circ}$ or $345^{\circ}$. As in the previous case, the lowest magnitudes for both local maximum and minimum $C p_{\text {, net }}$ values were found to occur when the canopy is placed at the leeward wall.

Clearly, wind direction has a significant impact on the local peak $C p_{\text {,net }}$. It has been noted that the response of peak $C p_{\text {,net }}$ values to wind direction is different for every configuration. For this reason, every peak $C p$ and $C p_{\text {, net }}$ value presented subsequently on this paper refers to its corresponding critical wind direction unless otherwise stated.

\section{Visualization of flow around the canopy}


Flow visualization experiments have been performed for a canopy attached to mid-height and near the eave height of the parent wall. Still shots for zero degree wind direction are provided in Figures 10 and 11 for these configurations. For a canopy attached at the mid height, stagnation of flow occurs at the parent wall both above and below the canopy. Stagnation of flow above the canopy will result in a downward flow running along the surface of the parent wall which will ultimately inflict a downward force on the upper surface of the canopy. Stagnation of flow in the parent wall underneath the canopy will in turn generate flow directed towards the lower surface of the canopy resulting in an upward force. These two counteracting forces at upper and lower surfaces are expected to result in a decreased net uplifting pressure coefficient $\left(\min C p_{\text {,net }}\right)$.

In the case of a canopy attached closer to the eave height, flow stagnates significantly at the parent wall underneath the canopy (see Fig. 11) resulting in a dominating upwards flow which generates a force directed towards the lower surface of the canopy. In contrast, high levels of flow separation occur at the upper surface of the canopy resulting in dominating suctions. The combination of high suctions acting on the upper surface and high pressures on the lower surface is expected to result in an increased uplifting force, i.e. a higher net uplifting pressure coefficient.

It can thus be expected that the higher the location of the canopy along the parent wall, i.e. the higher the $\frac{h c}{h}$ ratio, the higher the net uplifting pressures will be. Conversely, it may also be expected that higher net downward forces occur for lower $\frac{\boldsymbol{h} c}{\boldsymbol{h}}$ ratios.

\section{Net pressures and correlation coefficients}

Instrumentation of the canopy model with pressure taps at both upper and lower surfaces allows

for the monitoring of pressure coefficients at either surface separately $\left(C p_{\text {,upper }} ; C p_{\text {,lower }}\right)$ or 
their simultaneous effect at the same position of the canopy $\left(C p_{\text {,net }}\right)$. This provides the possibility of a clearer understanding of the wind loading patterns that the attached canopy is exposed to. Pressure and correlation coefficient contour plots for a canopy attached to both the mid-height, and eave height of the parent wall are given in Figures 12 and 13 respectively again for a zero degree wind direction.

Figure 12 shows that for a wind direction perpendicular to the parent wall, the upper surface of the canopy experiences downward loading of higher magnitudes than the suctions. In the lower surface, pressures are significantly higher than suctions as well. It must be noted however, that despite having a peak max $C p_{\text {,lower }}$ of more than 1.20 , the peak min $C p_{\text {, net }}$ was found to be 0.20. This phenomenon of counteracting forces can be further observed by the correlation coefficient contour plot (see Fig. 12) exhibiting high positive values between upper and lower surfaces of the canopy. It can be seen that the combined effect of pressures acting on upper and lower surfaces of canopies placed far from the eave (lower $\frac{\boldsymbol{h} c}{\boldsymbol{h}}$ ratios) will result in significant reductions to the loads experienced on either side, thus resulting in a reduced $\min C p$,net.

In contrast, Figure 13 shows that for a canopy placed closer to the eave height dominant suctions occur on the upper surface in combination with dominant pressures on the lower surface. The high suctions on the upper surface, particularly along the corners and leading edges, are attributed to the phenomenon of flow separation (refer to Fig. 11 for flow visualization photograph). The dominant high pressures on the lower surface of the canopy result from the upward flow generated by the stagnation of flow underneath the surface of the canopy. In this case a peak min $C p_{\text {,upper }}$ of -2.30 , in combination with a peak max $C p_{\text {,lower }}$ of 0.60 (not at the same location), results in a peak min $C p_{\text {,net }}$ of -2.70 . The correlation coefficients for this 
configuration range from weak to zero implying that the high suctions occurring at the upper surface of the canopy do not occur in a well-defined pattern with the positive pressures on the lower surface of the canopy. This can be reflected by the fact that the min $C p$,net value is increased, but only by a small amount over the individual contribution of the min $C p_{\text {,upper }}$ and $\max C p_{\text {,lower }}$ to the net uplifting forces on the canopy. Despite their weak correlation, the combined effect of the high suction and high pressure contributions at upper and lower surfaces respectively, result in an increase $\min C p_{\text {, net }}$ for higher $\frac{h c}{h}$ ratios.

It has been found, however, that peak $C p_{\text {,net }}$ values do not necessarily occur for wind directions perpendicular to the length of the canopy. Pressure and correlation coefficient contour plots for a canopy attached at the mid height of the parent wall are given in Figure 14 for the critical wind direction. When compared to the contours for a zero degree wind direction for the same configuration (refer to Fig. 12) it can be seen that the peak min $C p_{\text {,upper }}$ is significantly increased at the leftmost corner and the peak max $C p_{\text {,lower }}$ is decreased. Furthermore, the correlation coefficient at the same corner has been decreased. As a result, the peak min $C p_{\text {,net }}$ has been increased significantly in comparison with the zero degree wind direction.

Pressure and correlation coefficient contour plots for a canopy attached near the eave height of the parent wall are given in Figure 15 for the critical wind direction. When compared to the contours for a zero degree wind direction for the same configuration (see Fig. 13), it can be seen that the min $C p_{\text {,upper }}$ and $\max C p_{\text {,lower }}$ are significantly increased at the rightmost corner. It may be also seen that the correlation coefficient is slightly increased. As a result the min $C p_{\text {,net }}$ is increased by nearly 1.5 times the magnitude of that found for the zero degree wind direction. It is 
to be noted that the peak min $C p_{\text {,net }}=-3.89$ recorded was the largest observed for any configuration examined.

\section{Effect of geometric parameters on critical net pressure coefficients}

In this section the impact that each parameter has on the loads exerted upon the canopy is examined. This is done by varying a single parameter while maintaining the others constant. Four dependant variables are investigated for each case: the local minimum and maximum $C p_{\text {,net }}$ (Loc. Min. ; Loc. Max.), which refer to the critical values experienced at a single pressure tap pair, and the area-averaged minimum and maximum $C p_{\text {,net }}$ (Area-avg. Min. ; Area-avg. Max.), which refer to the peak value that the entire area experiences determined by the critical simultaneous averages at every pressure tap pair.

\section{a. Effect of $\frac{h c}{h}$}

Local and area-averaged $C p_{\text {,net }}$ values as a function of the $\frac{\boldsymbol{h} \boldsymbol{c}}{\boldsymbol{h}}$ ratio are presented in Figure 16. Clearly, a higher location of the canopy along the parent wall will generally result in higher net uplifting pressures ( $\min C p_{\text {,net }}$ ) on the canopy. It may also be noted that for $\frac{\boldsymbol{h} \boldsymbol{c}}{\boldsymbol{h}}$ ratios smaller than 0.5 , peak min $C p_{\text {,net }}$ values display little sensitivity to a slight increase in the canopy height. For intermediate heights $\left(0.5<\frac{h c}{h}<0.9\right)$ a higher sensitivity is observed as the slope for the local peak min $C p_{\text {,net }}$ is increased. Finally, for $\frac{\boldsymbol{h} \boldsymbol{c}}{\boldsymbol{h}}$ values greater than or equal to 0.9 a more notable increase occurs. The change from a low to a high $\frac{h c}{h}$ ratio can result in an increase of more than $3 x$ the magnitude of the peak local min $C p_{\text {,net }}$. It can thus be concluded that net uplifting pressures are highly sensitive to the $\frac{\boldsymbol{h} \boldsymbol{c}}{\boldsymbol{h}}$ ratio. This is consistent with what was previously 
observed from the pressure coefficients contours. The net downward pressure coefficients (max $\left.C p_{\text {,net }}\right)$, on the other hand, portray a smaller sensitivity to the $\frac{h c}{h}$ ratio. Furthermore, Figure 16 shows that the area-averaged max $C p$, net shows similar, although less pronounced, characteristics with the local values. For instance, the highest maximum local $C p_{\text {, net }}$ encountered is only $1.3 \mathrm{x}$ larger than the smallest. In general, the net downward pressures are less sensitive to the $\frac{\boldsymbol{h} \boldsymbol{c}}{\boldsymbol{h}}$ ratio than the net uplifting pressures.

\section{b. Effect of $\frac{h c}{w c}$}

Local and area-averaged $C p_{\text {,net }}$ values as a function of the $\frac{h c}{w c}$ ratio are presented in Figure 17 for an $\frac{\boldsymbol{h} \boldsymbol{c}}{\boldsymbol{h}}$ ratio of 0.94 , since this showed to be more critical in Figure 16 . When the width of the canopy $(\boldsymbol{w c})$ is decreased while maintaining its $\frac{\boldsymbol{h} \boldsymbol{c}}{\boldsymbol{h}}$ ratio constant, the net uplifting forces will initially increase, which can be explained by the reduction of surface area for the reattachment of flow to take place. However, when the width is further reduced the vortices generated in the gap between the canopy and the roof overhang may have a greater influence on the net uplift forces. This results in a marked reduction of both local and area-averaged min $C p_{\text {,net }}$ values. However, the highest local min $C p_{\text {, net }}$ encountered is only 1.3 times larger than the lowest.

Net downward pressure coefficients, on the other hand, portray an inversely proportional relationship to the $\frac{h c}{w c}$ ratio, probably due to the effect of stagnation occurring at the portion of the parent wall located underneath the canopy. The portion of the total canopy area exposed to the strongest upward flow becomes more significant when $\boldsymbol{w c}$ is decreased. As a result, the net 
downward loading is decreased. The highest local max $C p_{\text {,net }}$ encountered is 2.5 times larger than the lowest.

Given that the proximity of the canopy to the roof overhang, as well as the dominance of upward flow are considered to be critical on the effect of $\frac{h c}{w c}$ ratio on a configuration with a high $\frac{h c}{h}$ ratio, the interest to examine the effect of $\frac{h c}{w c}$ on a lower $\frac{h c}{h}$ ratio arises.

Figure 18 shows the local and area-averaged $C p$, net values as a function of $\frac{\boldsymbol{h} \boldsymbol{c}}{\boldsymbol{w} \boldsymbol{c}}$ for an $\frac{\boldsymbol{h} \boldsymbol{c}}{\boldsymbol{h}}$ ratio of 0.34. Clearly at this lower $\frac{h c}{h}$ ratio the effect of $\frac{h c}{w c}$ on the net uplifting forces appears to be negligible for both local and area-averaged peak $C p_{\text {,net }}$ values. In the case of the net downward pressures, increasing $\frac{h c}{w c}$ results in a marked increase of the max $C p$,net values. This trend is contrary to that found for the case of high $\frac{h c}{h}$ ratio, but for lower $\frac{h c}{h}$ ratios, the downward flow along the parent wall is dominant over the upward flow. As a result, the portion of the total canopy area exposed to the strongest downward flow becomes more significant when wc decreases.

\section{c. Effect of canopy length (lc) and location (ed)}

The effects of the length of the canopy $(\boldsymbol{l c})$ and the largest edge-to-edge distance (ed) on the net pressure coefficients have been examined. Local and area-averaged $C p$,net values as function of the $\frac{\boldsymbol{e d}}{\boldsymbol{l} \boldsymbol{c}}$ ratio are presented in Figure 19 for $\frac{\boldsymbol{h} \boldsymbol{c}}{\boldsymbol{h}}=0.94$ and $\boldsymbol{w c}=3.65 \mathrm{~m}$. An increase of the $\frac{\boldsymbol{e d}}{\boldsymbol{l} \boldsymbol{c}}$ ratio generally corresponds to a decrease in the magnitude of the local $\min C p$,net, whereas the areaaveraged $\min C p_{\text {,net }}$ portrays little sensitivity. It should also be noted that the case of the fulllength canopy $\left(\frac{l c}{l}=1\right)$ has a significantly higher local min $C p$, net in comparison to the other two 
half-length canopy $\left(\frac{l c}{l}=0.5\right)$ cases. Thus the $\frac{l c}{l}$ ratio is significant for the net uplifting pressures, whereas the edge distance seems to be of secondary importance.

In the case of net downward pressure coefficients there appears to be no significant difference between the full-length canopy model and the half-length models. The same can be said about the distance from the edge, which shows only a slight increase when going from a canopy placed at the center $\left(\frac{e d}{l c}=0.5\right)$ to a canopy placed at the corner $\left(\frac{e d}{l c}=1\right)$ of the parent wall.

Therefore, local uplift forces are sensitive to changes in the $\frac{\boldsymbol{l}}{\boldsymbol{l}}$ ratio but less sensitive to the largest edge-to-edge distance $(\boldsymbol{e d})$. Local downwards wind-induced forces, on the other hand, are more sensitive to the $\frac{e d}{l c}$ ratio and display little sensitivity to the $\frac{\boldsymbol{l}}{l}$ ratio.

\section{Comparisons with experimental results of previous studies}

As previously stated, several wind standards and codes of practice containing provisions for the design of attached canopies show significant inconsistencies among themselves. Publications regarding the wind tunnel experimentation and analyses that led to the development of the AS/NZS and the DIN design provisions (Jancauskas and Holmes 1985; Hölscher et al. 2007) facilitate the comparisons between the experimental results of the present study and those from these studies. Figure 20 compares peak negative net pressure coefficients measured by Jancauskas and Holmes (1985) and those from the present study. These coefficients are based on dynamic velocity pressure evaluated from the mean hourly wind speed. For all cases considered, the results of the present study generally portray a good agreement with the previous results.

The experimental results and analyses that led to the design guidelines provided in the DIN (Hölscher et al. 2007) have been and compared with those of the present study in Figure 21. Peak 
net pressure coefficients are also based on dynamic velocity pressure evaluated from the mean hourly wind speed. The comparison shows that the results of the present study are higher, particularly for higher hc/h ratios. This may be attributed to the increased number of wind directions examined in the present study. For instance, within azimuths ranging from $30^{\circ}$ to $90^{\circ}$ the present study considers 6 different wind directions, as opposed to 3 in (Hölscher et al. 2007). This may have a significant impact on the critical peak coefficients. Additional notable differences include the different flow conditions (open country vs. suburban) and the different roof types (gable vs. flat) of the low-rise building.

\section{TOWARDS CODIFICATION}

In addition to the local pressure coefficients presented so far in this paper, area-averaged values are necessary for codification purposes. The area-averaging effect on min and max $C p_{\text {,net }}$ peaks has been determined by considering single or multiple sets of pressure taps and assigning them to their corresponding effective surface areas. The three plots shown in Figure 22 (for cases I, II, and III - see Fig. 5) contain all of the experimental results in terms of peak net pressure coefficients as a function of the effective area. Each plot contains 21 curves corresponding to all respective runs, as defined in Table 1 . The expected monotonically decreasing relationship between the effective area and the magnitudes of the peak pressure coefficients is clearly shown.

Based on the previous results regarding the effect of the $\frac{\boldsymbol{h} \boldsymbol{c}}{\boldsymbol{h}}$ ratio on peak $C p_{\text {,net }}$, all curves shown in Figure 22 have been grouped into one of the following three categories:

$$
\begin{aligned}
& >0.9 \leq \frac{h c}{h} \leq 1 \\
& >0.5 \leq \frac{h c}{h}<0.9
\end{aligned}
$$


$>\frac{h c}{h}<0.5$

Consequently, minimum envelope lines have been superimposed onto each plot. Please note that the envelope with the highest net uplifting peak is found for Case I $\left(\frac{\boldsymbol{e d}}{\boldsymbol{l c}}=0\right)$, whereas the highest net downward loading peak occurs for Case III $\left(\frac{\boldsymbol{e d}}{\boldsymbol{l c}}=1\right)$.

In the case of net downward loading it can be seen that the experimental curves for different $\frac{\boldsymbol{h} \boldsymbol{c}}{\boldsymbol{h}}$ ranges appear to be intertwined. This reaffirms the observation that net downward loads are less sensitive to the $\frac{h c}{h}$ ratio. For this reason a single maximum envelope is provided in Figure 22 for all $\frac{h c}{h}$ ratios.

Furthermore, the envelopes for Case I $\left(\frac{l c}{l}=1\right)$ are significantly higher than those for Cases II and III $\left(\frac{\boldsymbol{l}}{\boldsymbol{l}}=0.5\right)$. Also, the envelopes of Cases II and III present small differences with each other. This is consistent with the results shown in Figure 19, where $\frac{\boldsymbol{l}}{\boldsymbol{l}}$ has a significant impact on min local $C p_{\text {,net }}$ in contrast with $\frac{e d}{l c}$, which has very little effect.

\section{RECOMMENDATIONS}

Recommended provisions for the design of attached canopies are provided in Figure 23. It must be noted that all pressure coefficients presented from here on have been converted to conform to a 3-sec gust averaging period for codification purposes. The conversions were approximated by use of the Durst curve for gust duration (Durst 1960). 
These proposed design provisions have been generated from the envelopes of all experimental data obtained from this parametric study (see Fig. 22). The approach followed for the derivation of codified provisions was similar to previous codification work (Davenport et al. 1985).

Net pressure coefficient design values as a function of the $\frac{h c}{h}$ ratios and the effective area considered are presented in the two graphs shown. The first graph corresponds to a canopy extending over the entire length of the parent wall $\left(\frac{l c}{l}=1\right)$, and the second graph corresponds to a canopy extending over half of the length of the parent wall or less $\left(\frac{l c}{l} \leq 0.5\right)$. For the case of intermediate $\frac{l c}{l}$ ratios linear interpolation in between the $G C p_{\text {, net }}$ values of the two graphs may be used assuming that the lower diagram curves correspond to $\frac{l c}{l}=0.5$.

\section{COMPARISONS WITH CURRENT CODE PROVISIONS}

In this section, comparisons are made between the recommended design provisions of the present study and those of the AS/NZS and DIN.

\section{AZ/NZS 1170.2:2002}

Comparisons between the values proposed by the AS/NZS and the recommended envelopes of the present study for the $C p_{\text {,net }}$ as a function of the effective area are presented in Figure 24. In general a good agreement has been observed. It must be noted that for $\frac{\mathrm{hc}}{\mathrm{h}}=1$ the AS/NZS recommends considerably higher values than those recommended in the present study for the range of $0.9 \leq \frac{\mathrm{hc}}{\mathrm{h}} \leq 1$, particularly for local suctions. This marked increase in the AS/NZS provisions occurs when multiplying the recommended $G C p_{\text {,net }}$ by a Local net pressure factor of 
1.5 in accordance to Table D1 of the AS/NZS. For $\frac{\mathrm{hc}}{\mathrm{h}}=0.75$ in the AS/NZS a good agreement is seen with the range of $0.5<\frac{\mathrm{hc}}{\mathrm{h}}<0.9$ from the present recommendations. For $\frac{\mathrm{hc}}{\mathrm{h}}=0.5$, the $\min$ $G C p_{\text {,net }}$ recommended by the AS/NZS are considerably lower than the present recommendations. In the case of the max $G C p_{\text {, net }}$ it can be seen that the three different values corresponding to the $\mathrm{AS} / \mathrm{NZS}$ recommendations for $\frac{\mathrm{hc}}{\mathrm{h}}$ ratios of $1,0.75$, and 0.5 respectively, are all within the values of the present recommendations.

\section{DIN EN 1991-1-4/NA:2010-12}

Comparisons between the design provisions on the DIN and those of the present study are provided in Figure 25 as a function of $\frac{h c}{h}$ for three configurations. It can be seen that the recommended values for local min $G C p_{\text {,net }}$ generally display a good agreement in which the recommendations of the present study are slightly higher than the recommendations of the DIN. In the case of the local max $G C p_{\text {, net }}$, the DIN and the present study recommend the same values regardless of the $\frac{h c}{h}$ ratio for this range. It may also be noted that the recommendations of the present study for the highest downward loading is considerably higher than that recommended by the DIN.

\section{COMPARISONS WITH ASCE 7-10 PROVISIONS FOR OVERHANGS}

Due to the lack of provisions in the major North American codes and standards, practitioners often consider the attached canopies as extensions of the roof overhangs and design them in accordance with the corresponding design guidelines. However, as expected, this may result in significant differences with the experimental values obtained for attached canopies. Figure 26 presents the comparisons between the min $G C p_{\text {,net }}$ values provided by the ASCE 7 provisions for 
roof overhangs and the present recommendations for a canopy extending over the entire length of the parent wall. These marked differences denote the significant economic benefit to the design of canopies if the recommended provisions are adopted. However, the effect of the roof slope has also been seen to have an effect on the pressures around the heavily-loaded corner regions.

\section{SUMMARY AND CONCLUSIONS}

Wind tunnel experimentation has been performed on a total of 63 different configurations to serve as the basis for a parametric study of the wind loading on attached canopies. The effect of wind direction on net pressure coefficients has been examined and it has been shown that the critical peaks may occur for different wind directions depending on the configuration. Local and area-averaged net pressure coefficients have been analyzed as a function of four basic geometric ratios to examine the trends and relationships that they exhibit with each other. Pressure and correlation coefficient contour plots have also been presented in order to provide a better understanding of the flow patterns occurring around the canopy. It was concluded that amongst the four geometric ratios considered, $\frac{\mathrm{hc}}{\mathrm{h}}$ has the greatest influence on the local uplift $G C p_{\text {, net }}$.

Recommended design provisions appropriate for ASCE 7 are presented, as a result of the results of the present study.

Comparisons between the recommended design provisions and those established in the AZ/NZS 1170.2:2011 and DIN EN 1991-1-4/NA:2010-12 have been made. It was shown that these provisions are similar - for some cases higher and others lower - when compared to the present recommendations. 
Finally, a comparison between the recommended design provisions of the present study and those of the ASCE 7 for the design of roof overhangs shows the significant economic benefit if the recommended provisions are adopted.

\section{References}

ASCE. (2010). "Minimum design loads for building and other structures." ASCE/SEI 7-10, Reston, Va.

AZ/NZS (2011), "Australian/New Zealand standards, structural design actions-Part 2, wind actions." AS/NZS 1170.2:2011, Sydney, Au.; Wellington, NZ.

British Standard Institute. (1997). "Loading for buildings—Part 2: Code of practice for wind loads." BS 6399-2, London.

CEN. (2004). "Eurocode 1: Actions on structures-General actions-Part 1.4: Wind actions." $\mathrm{Pr}$ EN 1991-1-4, Brussels.

Davenport, A.G., Stathopoulos, T., Surry, D. (1985) "Reliability of wind loading specifications for low Buildings." Proc., Int. Conf. on Structural Safety and Reliability, ICOSSAR 85, Kobe, Japan.

DIN. (2005). "Einwirkungen auf Tragwerke - teil 4: Windlasten" DIN1055-4:2005-03, Berlin.

Durst, C.S. (1960). "Wind speeds over short periods of time.” Meteorological Magazine., 89, 181-186.

Goyal, R., Ahuja, A.K., and Prasad. J. (2007) "Wind loads on buildings with attached canopies", Asian Journal of Civil Engineering, Vol. 8 No. 3, 239-246

Hölscher, N., Hubert, W. and Niemann H.J. (2007) "Normgemäße Erfassung der Windwirkungen an Vordächern Vordächern" Fachteil WtG, Band 82, S.S2-S5, ISSN 1434-6591

International Code Council. (2006a). International building code (IBC), Fall Church, Va.

International Code Council. (2006b). International residential code (IRC), Fall Church, Va. 
IS. (1987). "Indian Standard code of practice for design loads-(Part 3-wind loads) for buildings and structures" IS: 875 (Part-3)-1987, New Delhi.

Jancauskas, L., and Holmes, J. (1985). "Wind loads on attached canopies." Proc., National Conf. on Wind Engineering, Texas Tech Univ., Lubbock, Tex.

National Research Council of Canada. (2010). National Building Code of Canada (NBCC), Ottawa, ON.

ÖNORM. (1993). "Belastungsannahmen im Bauwesen - Statische Windeinwirkungen” ÖNORM B 4014-1:1993 05 01, Vienna.

Paluch, M.J., Loredo-souza, A.M. and Blessmann, J. (2003). "Wind loads on attached canopies and their effects on the pressure distribution over arch roof industrial building", J. Wind. Eng. Ind. Aerodyn., 91, 975-994.

SIA (2003), "Einwirkungen auf Tragwerke, Schweizerischer ingenieur- und Architektenverein". SIA 261:2003, Zurich

Uematsu, Y., Iizumi, E., and Stathopoulos, T. (2007). "Wind force coefficients for designing free-standing canopy roofs." J. Wind. Eng. Ind. Aerodyn., 95_9-11_, 1486-1510.

Uematsu, Y., Stathopoulos, T., and Iizumi, E. (2008a). "Wind loads on free-standing canopy roofs: Part 1. Local wind pressures.” J. Wind. Eng. Ind. Aerodyn., 96_6-7_, 1015-1028.

Uematsu, Y., Stathopoulos, T., and Iizumi, E. (2008b). "Wind loads on free-standing canopy roofs: Part 2. Overall wind forces." J. Wind. Eng. Ind. Aerodyn., 96_6-7_, 1029-1042.

Zisis, I. and Stathopoulos, T. (2010). "Wind-induced pressures on patio covers" J. Str. Eng., Volume 136, No. 9, pp. 1172-1181. 


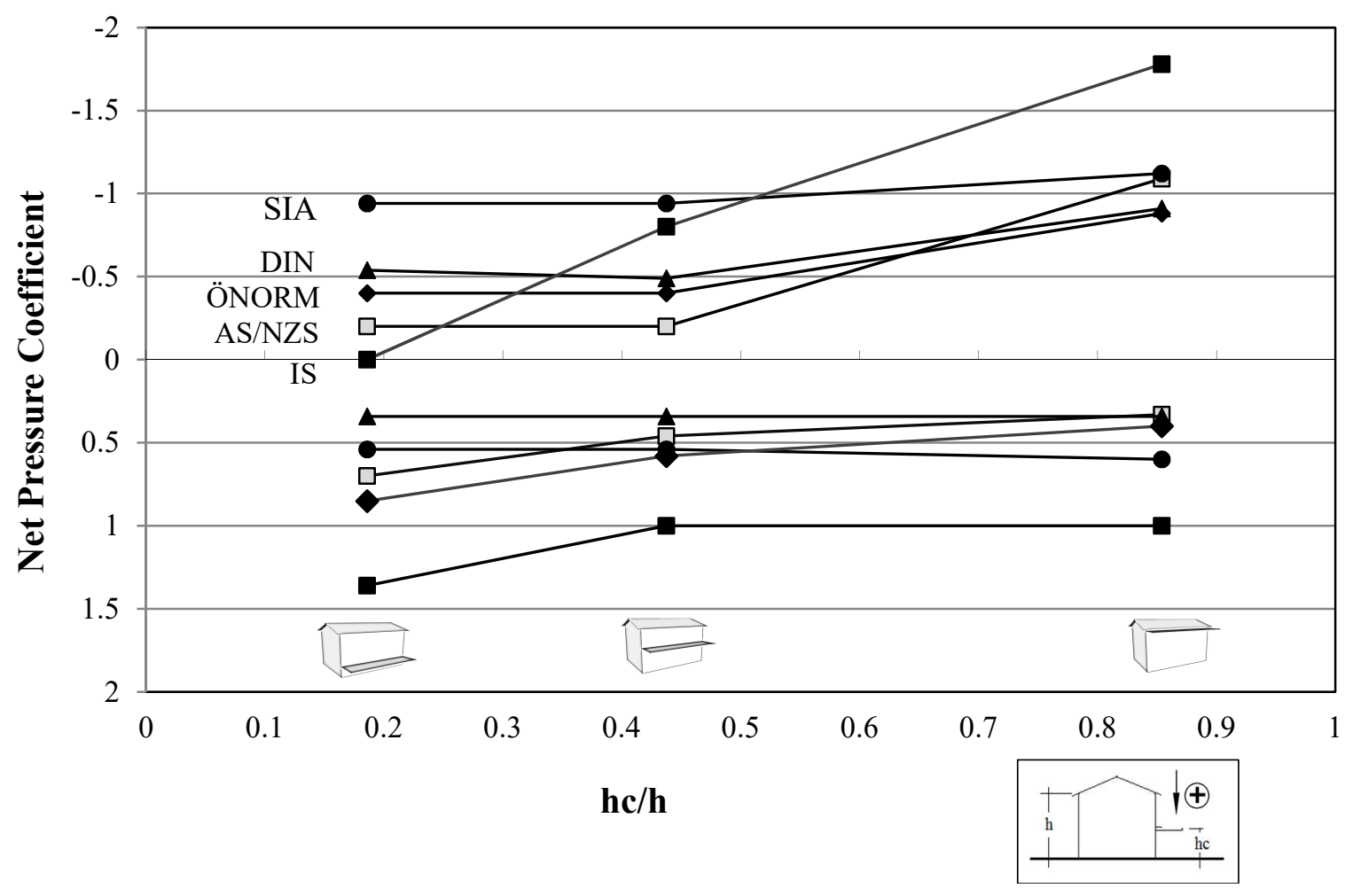

Fig. 1 Local net pressure coefficients for the three buildings illustrated as obtained from the labeled design code provisions
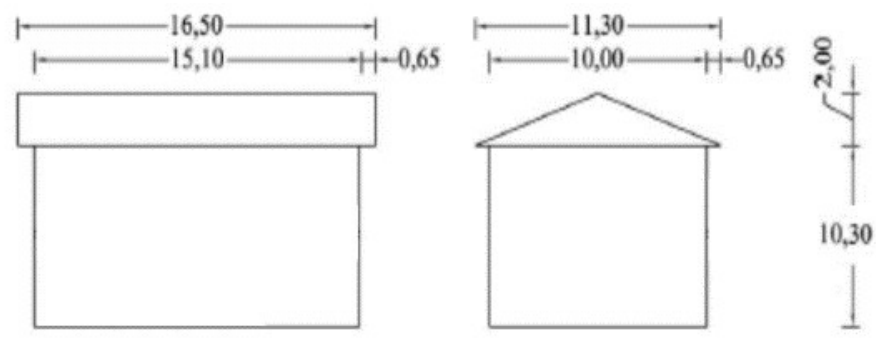

Fig. 2 Building configuration tested 

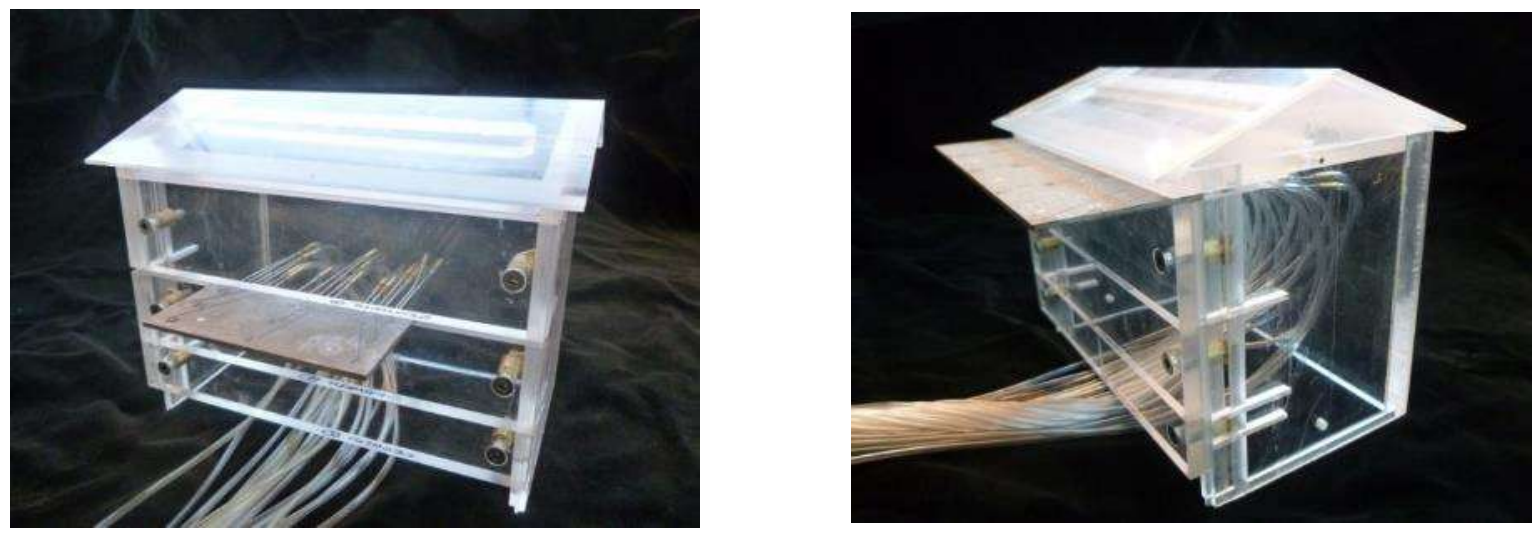

Fig. 3 Building model with different canopies
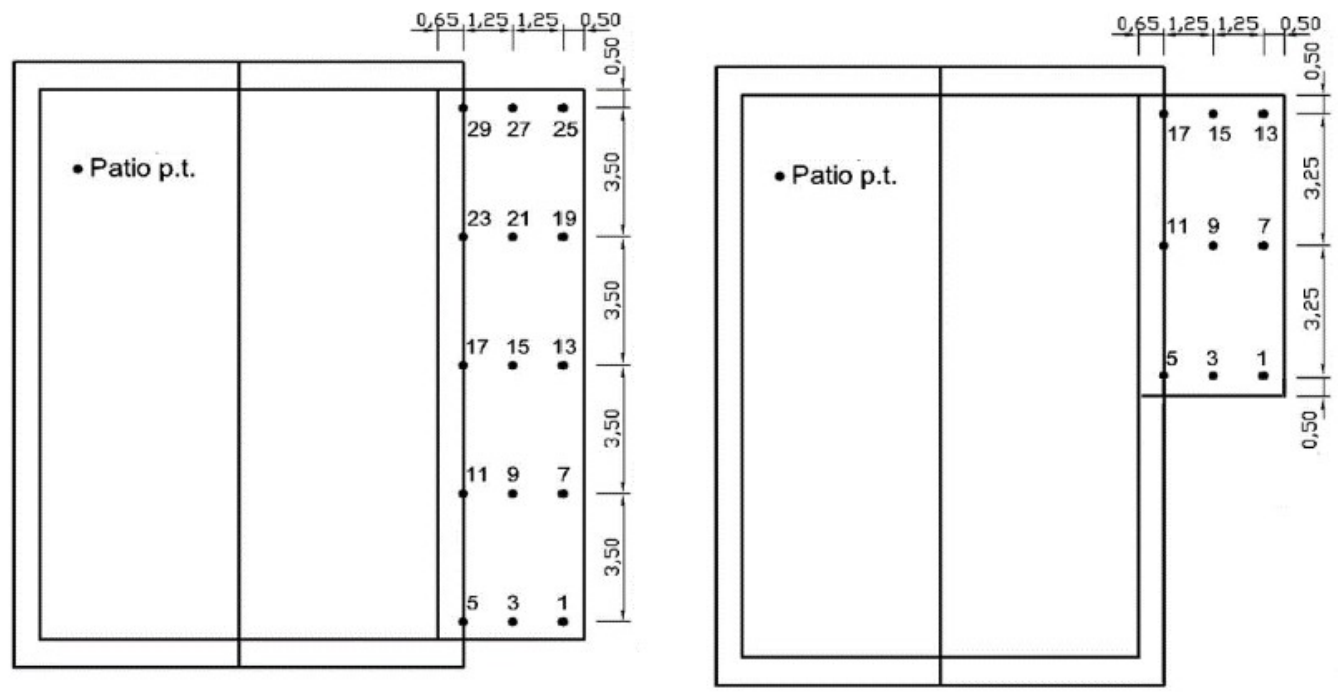

*even numbered channels are located underneath the tappings shown

Fig. 4 Top view of building and canopy model showing pressure tap locations 


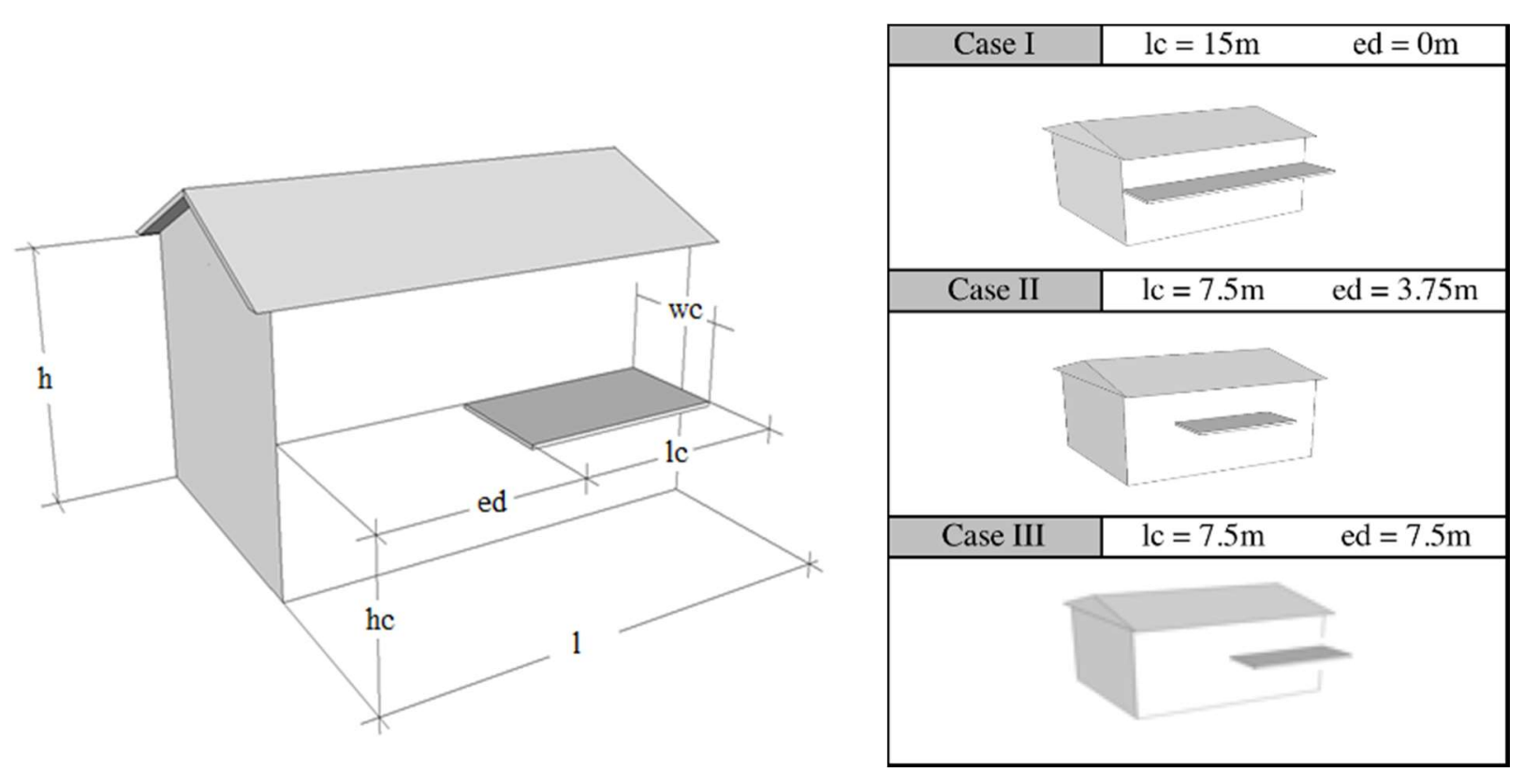

Fig. 5 Configuration of the three principal cases tested in terms of the canopy length (1) and edge-to-edge distance $\left(e_{d}\right)$ 


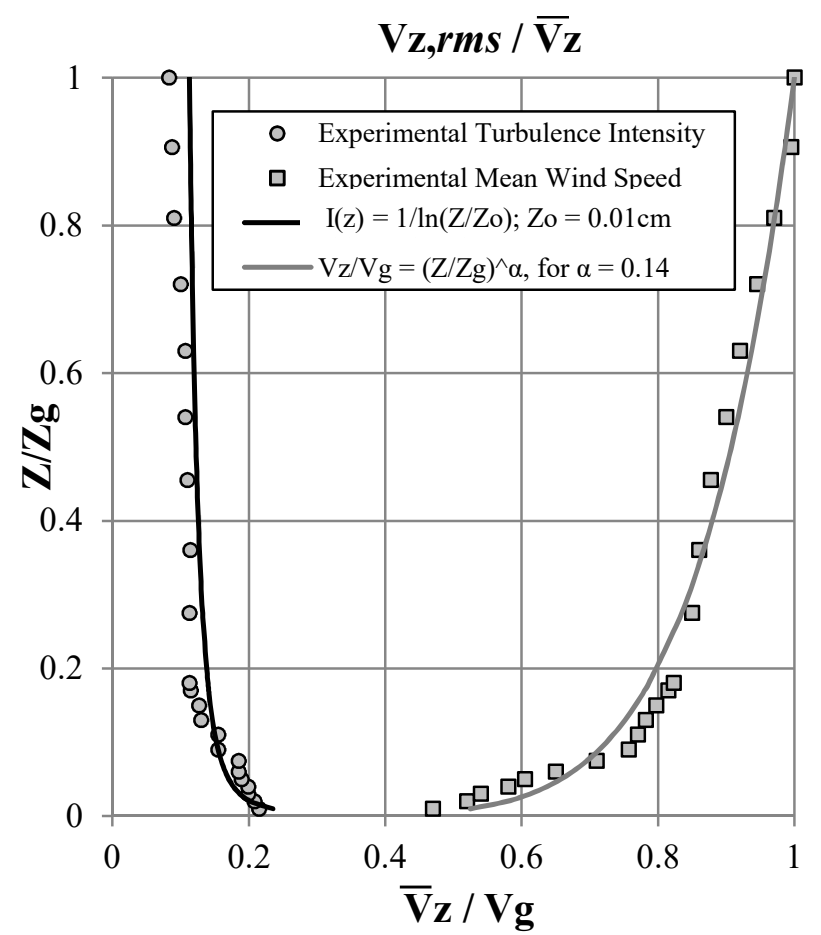

Fig. 6 Velocity and turbulence intensity profiles

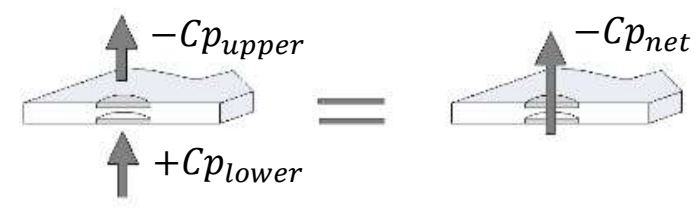

Fig. 7 Illustration of the generation of net pressure coefficients, $\mathrm{Cp}$, net 


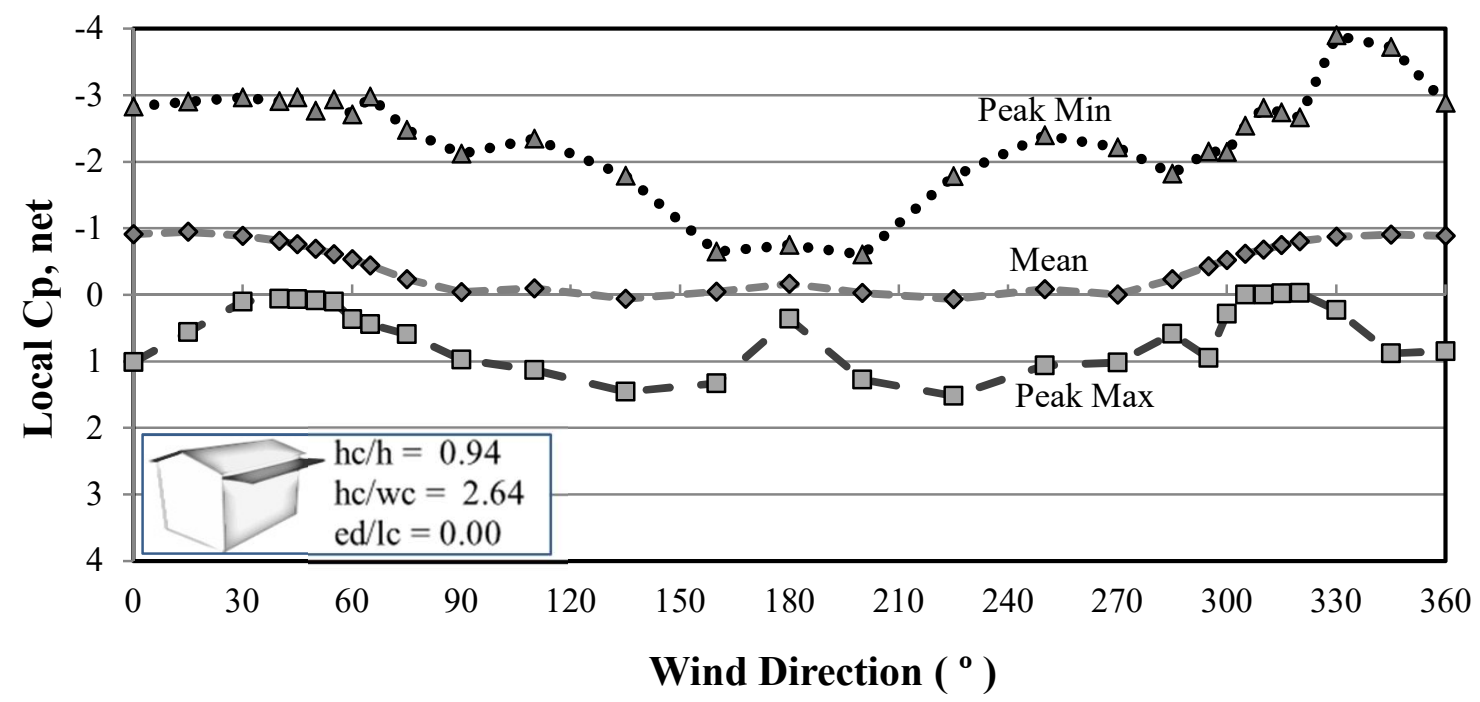

Fig. 8 Effect of wind direction on local peak minimum, peak maximum and mean $C p_{\text {, net }}$ for a canopy extending over the full length of the parent wall

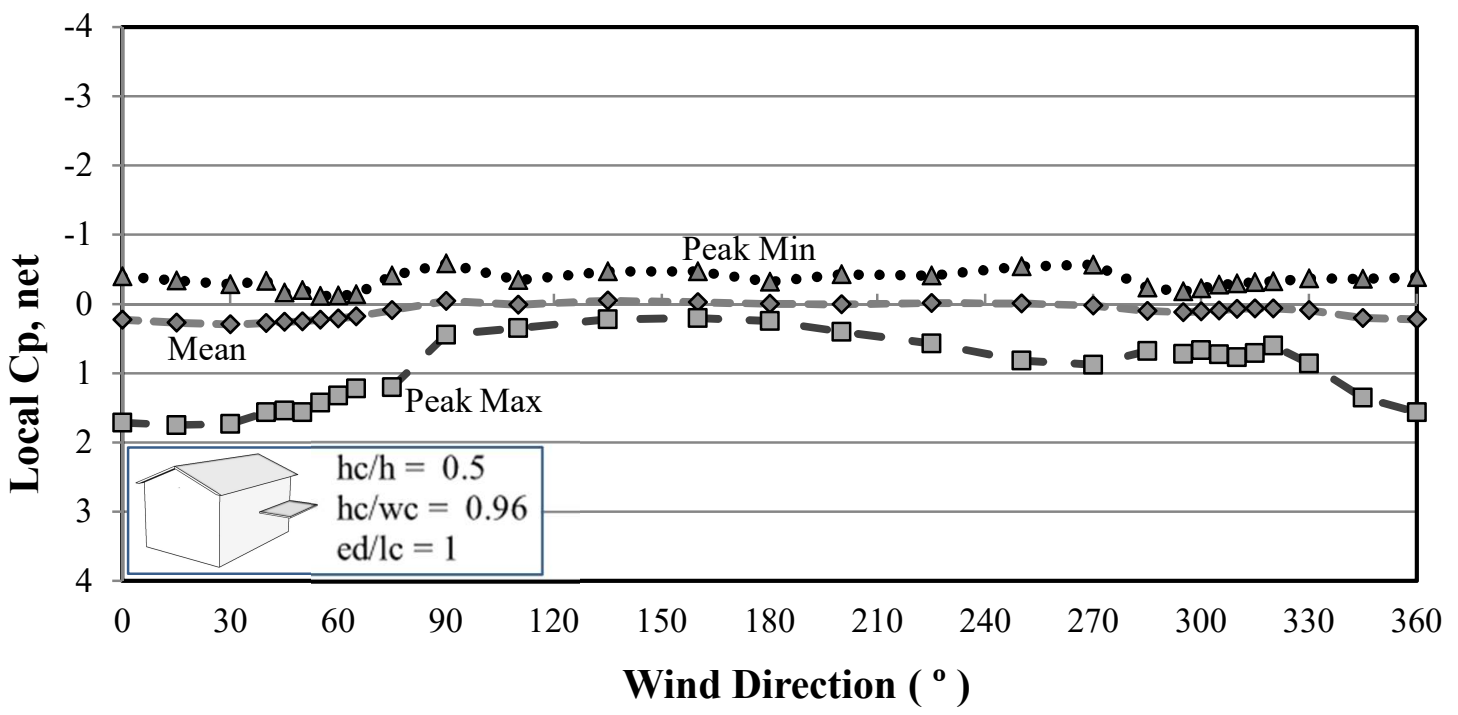

Fig. 9 Effect of wind direction on local peak minimum, peak maximum and mean $C p_{\text {, net }}$ for an eccentrically placed canopy extending over half of the length of the parent wall 


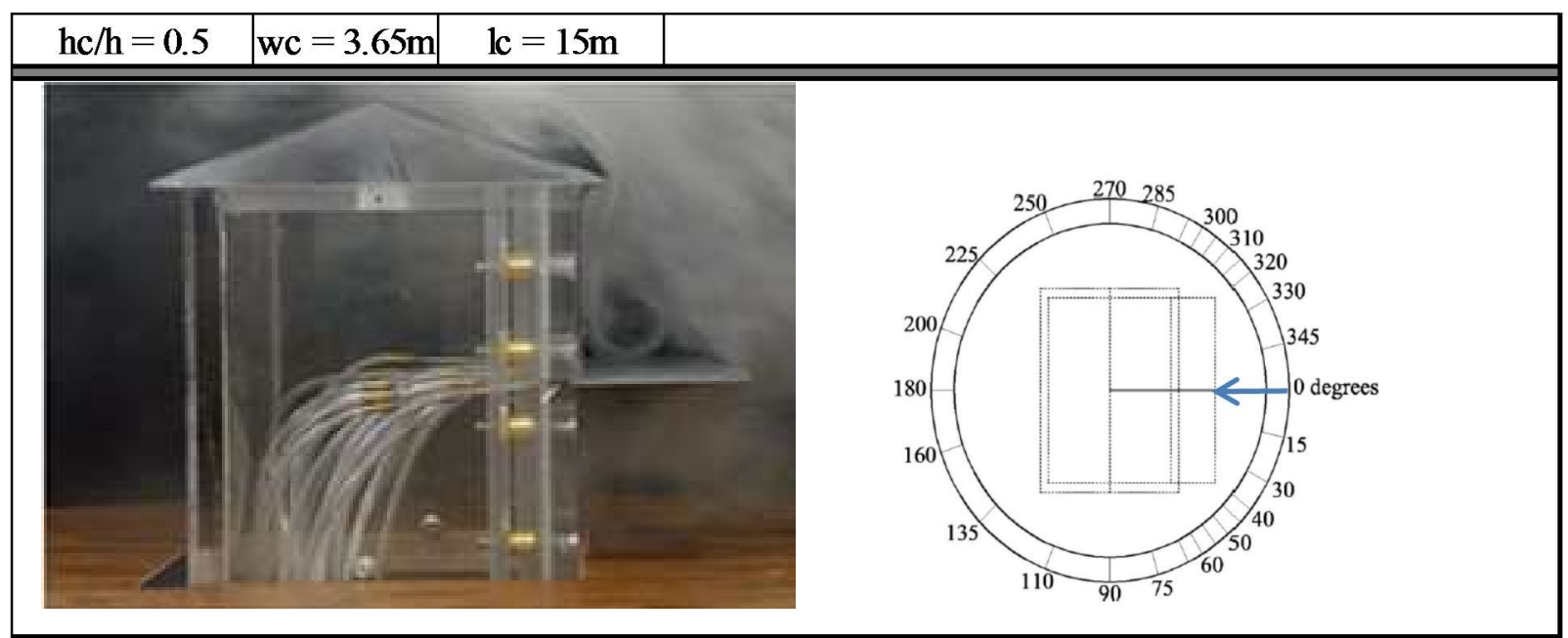

Fig. 10 Flow visualization for a canopy attached at the mid height of the parent wall and a zero degree azimuth

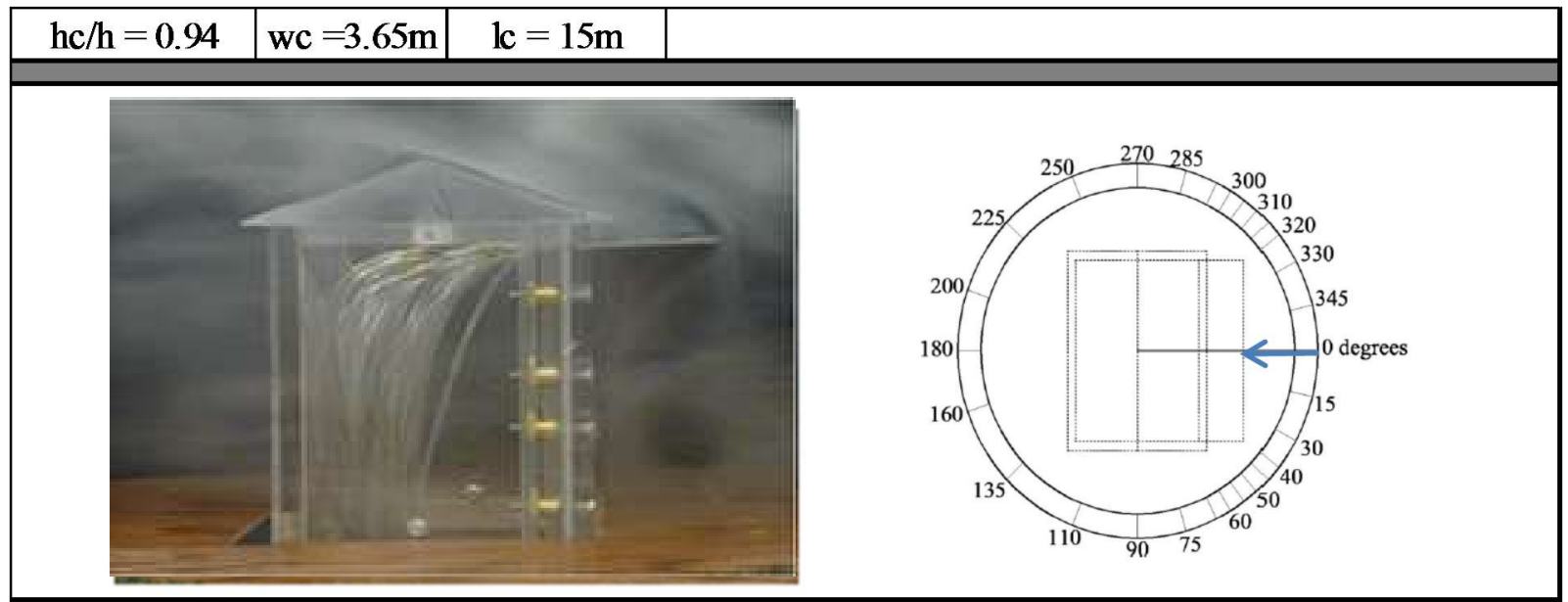

Fig. 11 Flow visualization for a canopy attached close to the eave height of the parent wall and a zero degree azimuth 


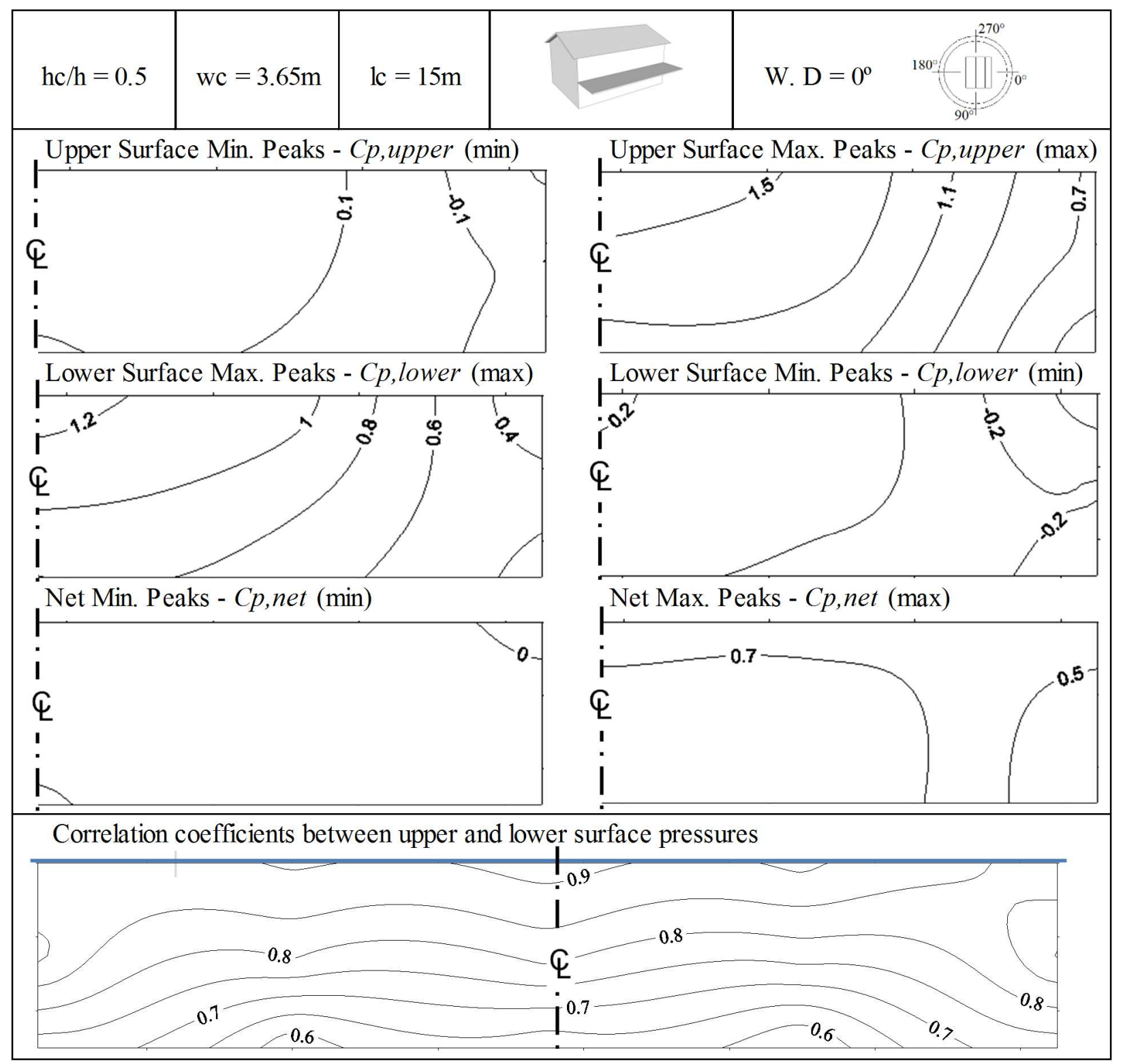

Fig. 12 Pressure and correlation coefficient contour plots for a canopy attached at the mid height of the parent wall and a zero degree azimuth 


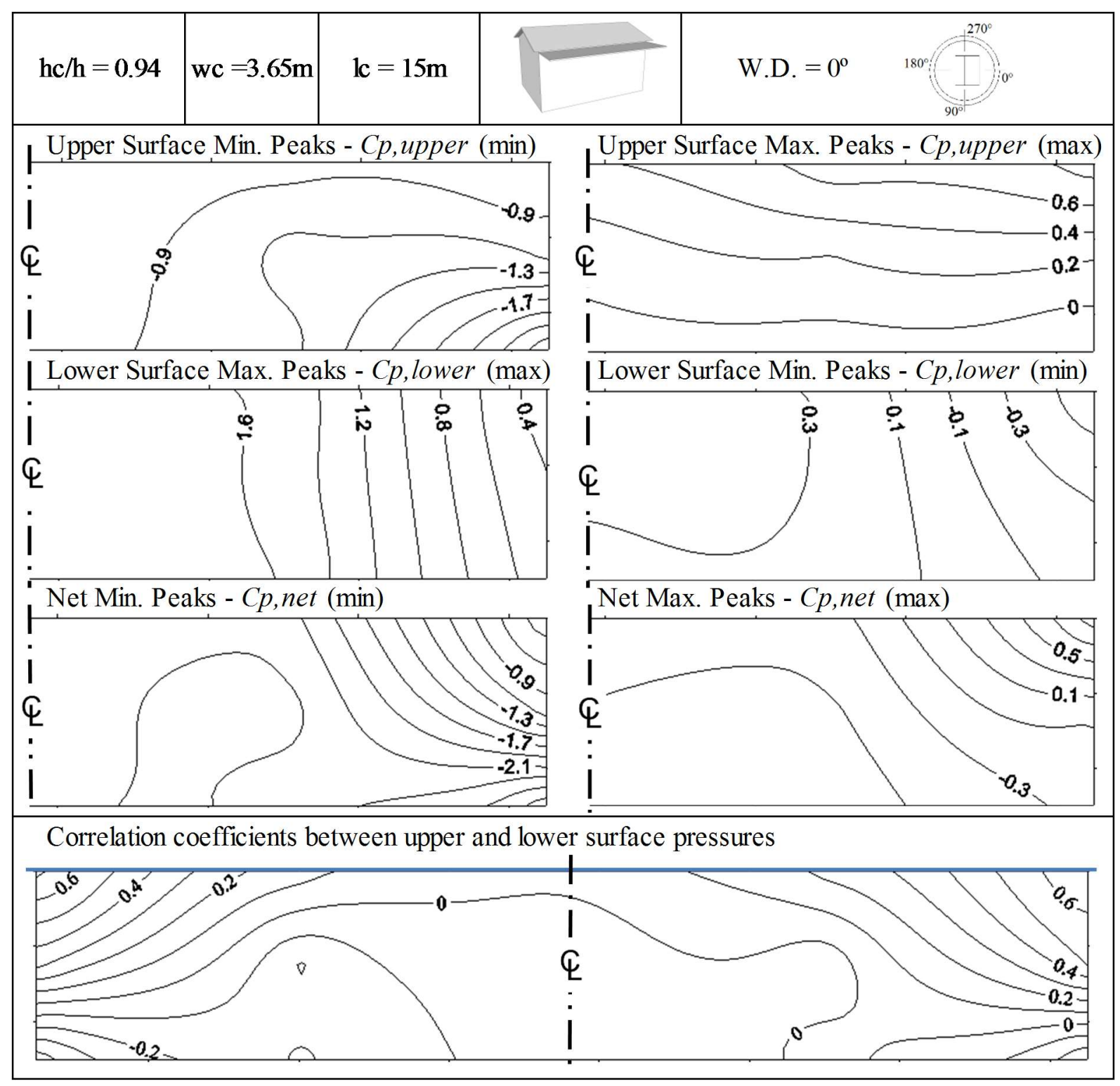

Fig. 13 Pressure and correlation coefficient contour plots for a canopy attached close to the eave height of the parent wall and a zero degree azimuth 


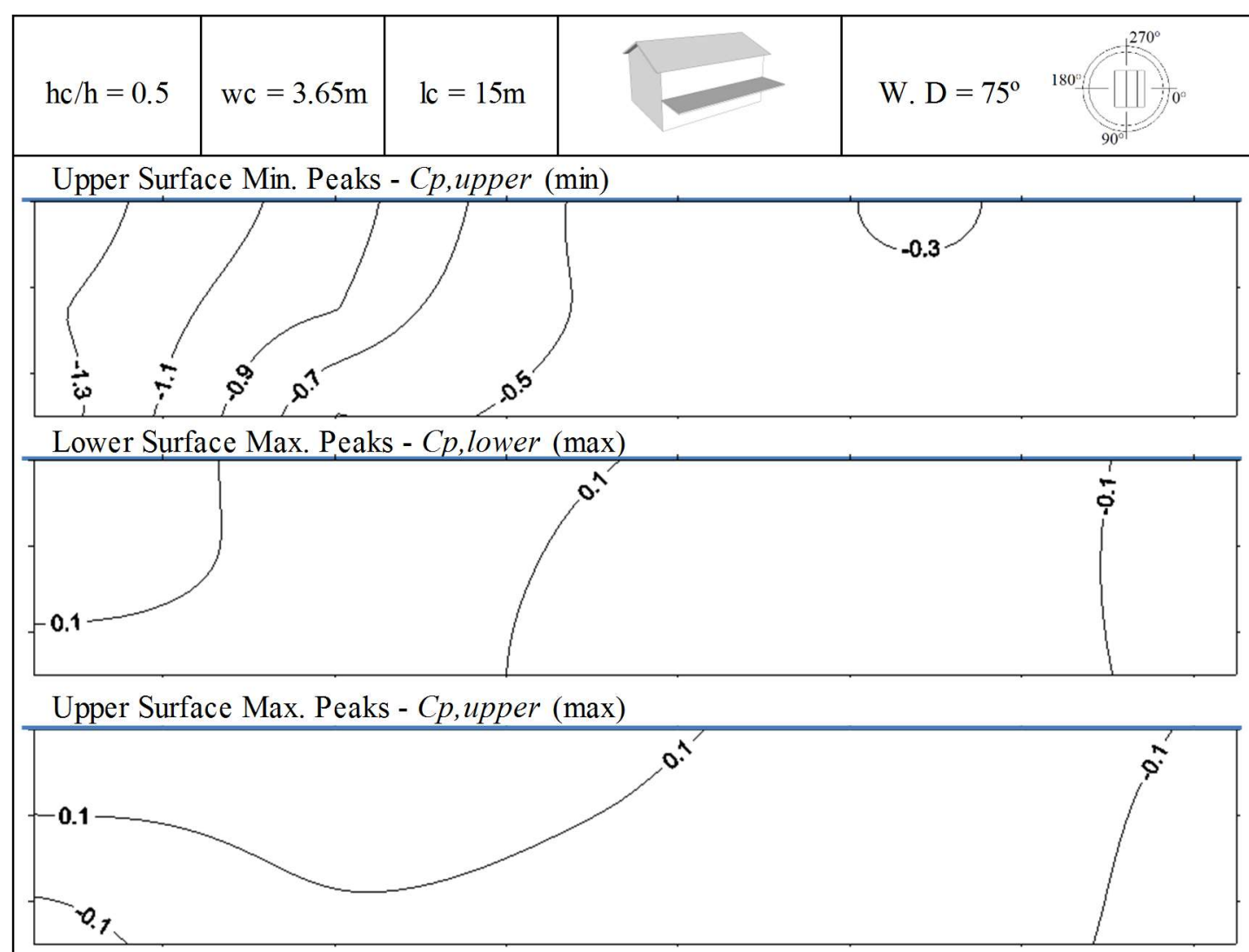

Lower Surface Min. Peaks - Cp,lower (min)

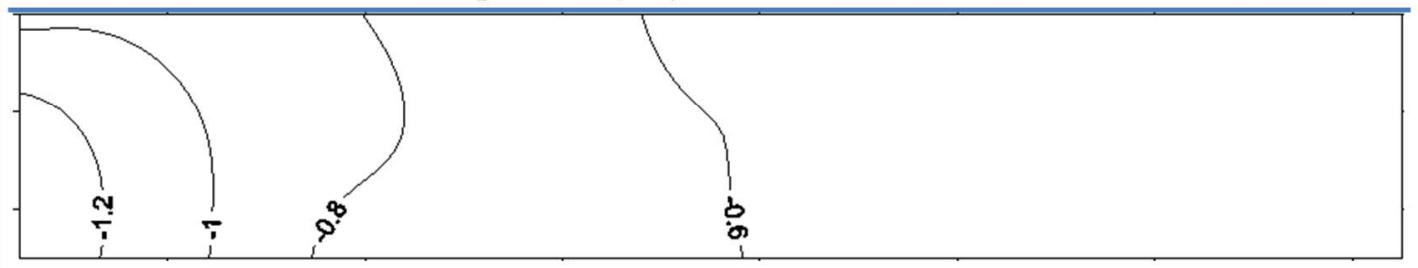

Net Min. Peaks - Cp, net $(\min )$

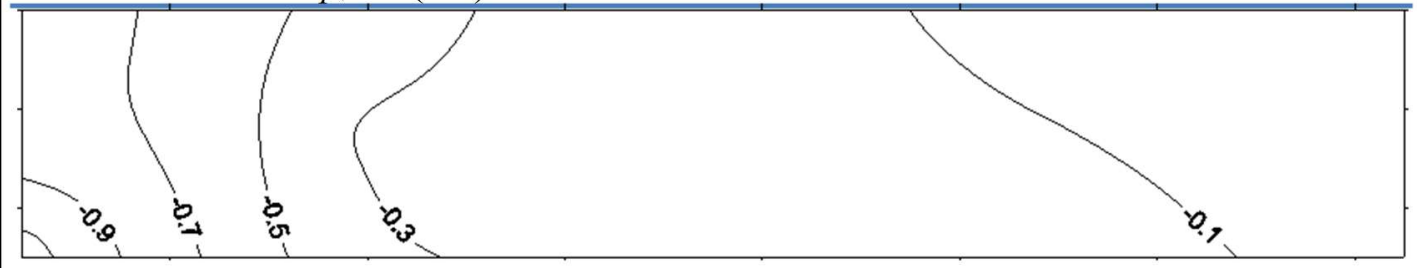

Correlation coefficients between upper and lower surface pressures

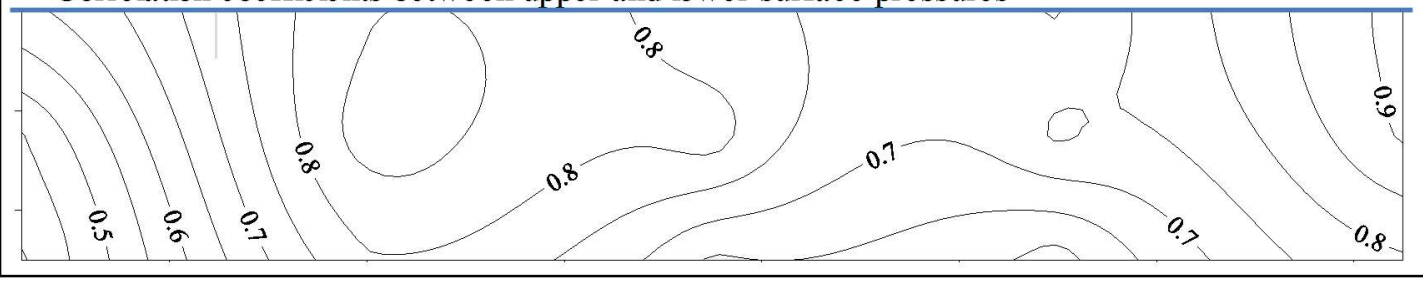

Fig. 14 Pressure and correlation coefficient contour plots for a canopy attached at the mid height of the parent wall and the critical wind direction $\left(75^{\circ}\right)$ 


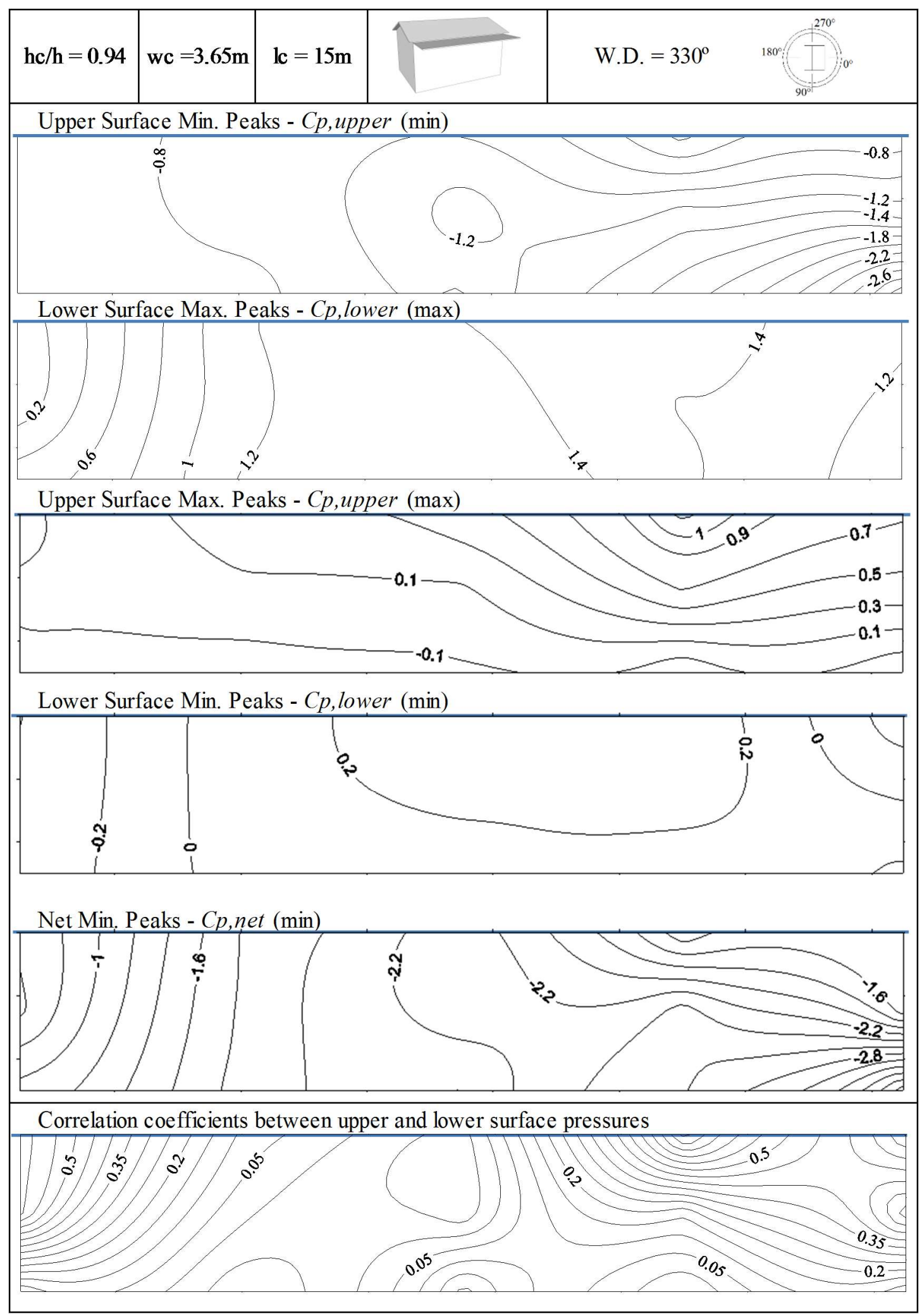

Fig. 15 Pressure and correlation coefficient contour plots for a canopy attached close to the eave height of the parent wall and the critical wind direction $\left(330^{\circ}\right)$ 


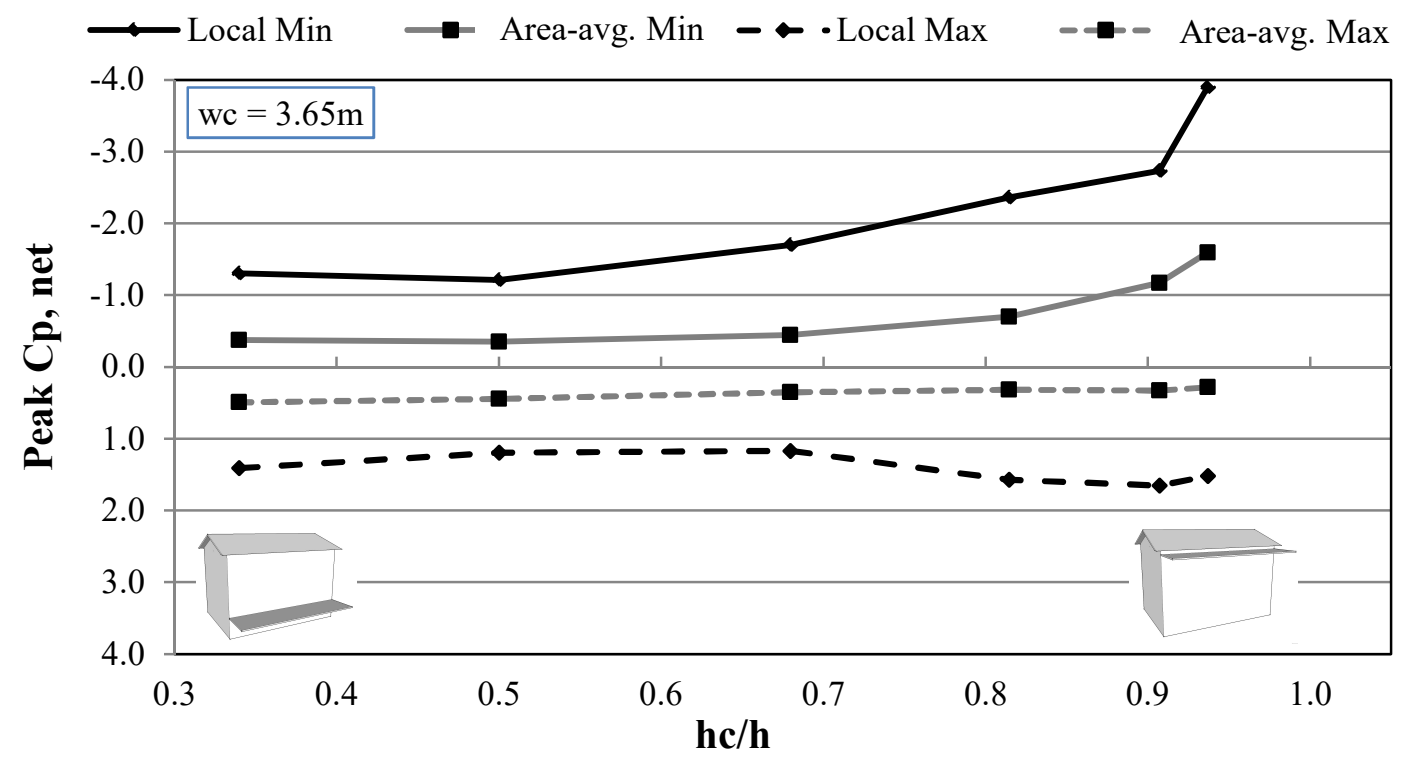

Fig. 16 Effect of hc/h on local, and area-averaged $C p_{\text {,net }}$ for $\boldsymbol{w c}=3.65 \mathrm{~m}$

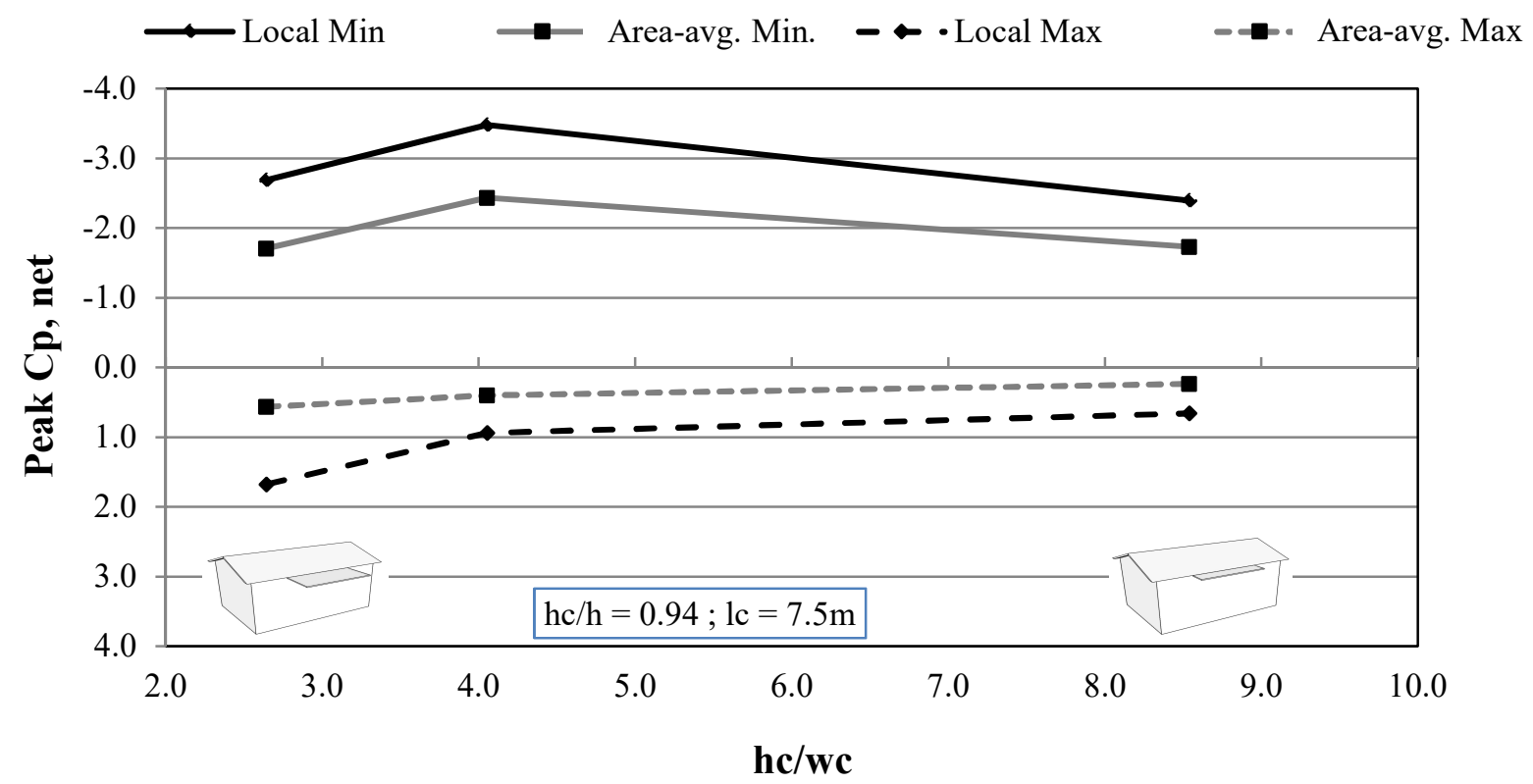

Fig. 17 Effect of $\frac{h c}{w c}$ on local and area-averaged $C p_{\text {,net }}$ for $\frac{h c}{h}=0.94$ 


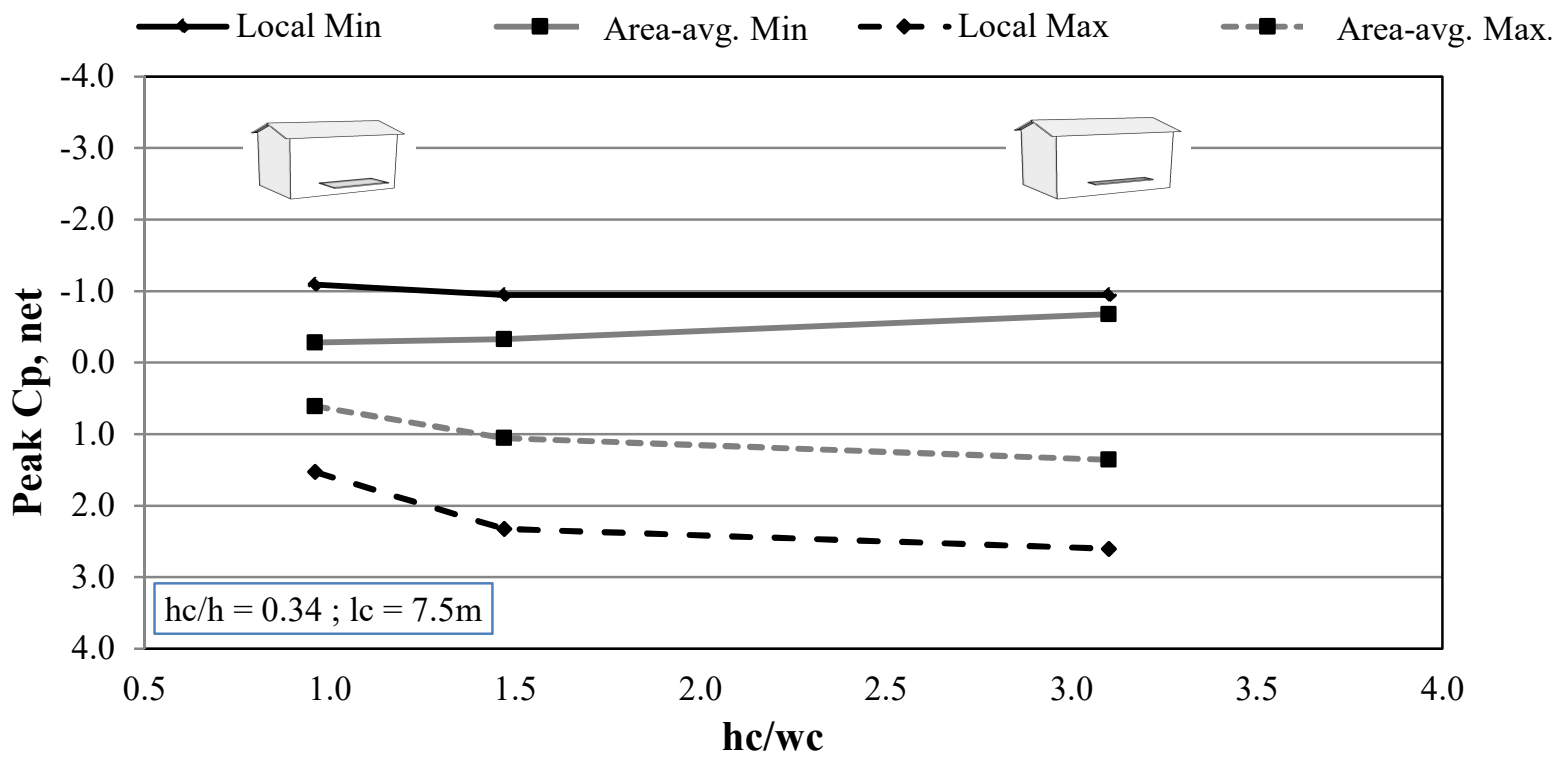

Fig. 18 Effect of $\frac{h c}{w c}$ ratio on local and area-averaged $C p_{\text {, net }}$ for $\frac{h c}{h}=0.34$

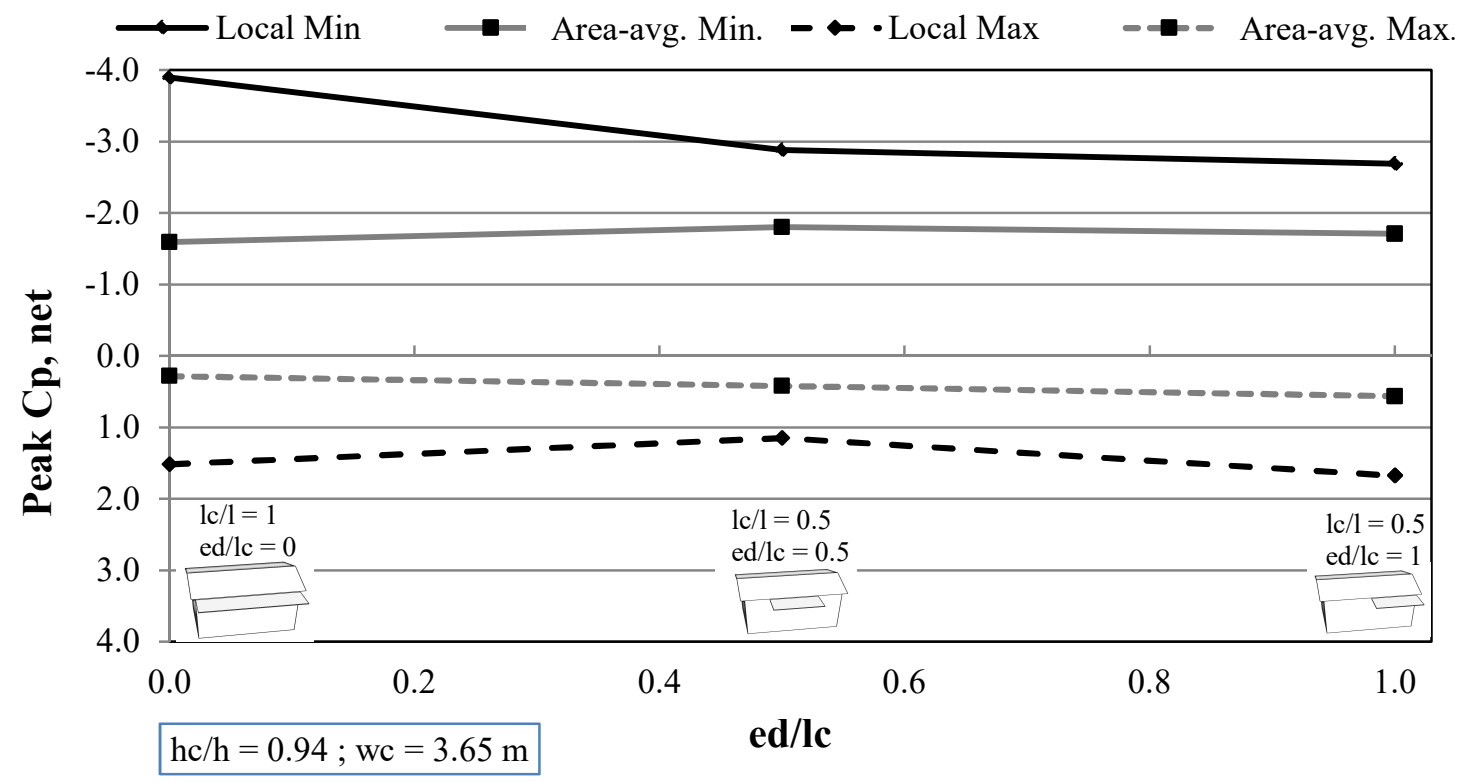

Fig. 19 Effect of length and edge distances on local and area-averaged $C p_{\text {,nets }}$ for $\frac{\mathrm{hc}}{\mathrm{h}}=0.94$ and $\mathrm{wc}=3.65 \mathrm{~m}$ 

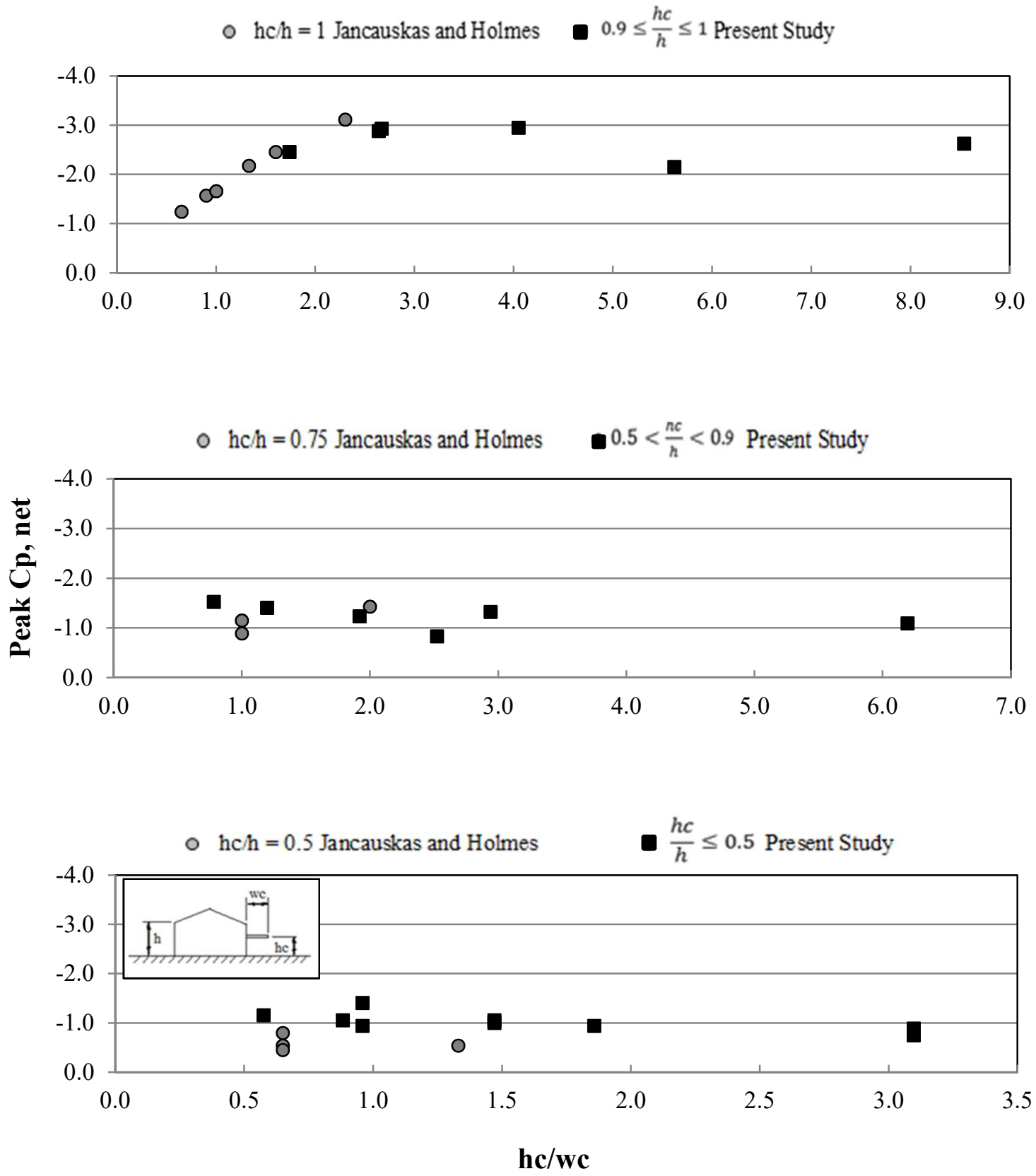

Fig. 20 Comparison between results of the present study and those of Jancauskas and Holmes (1985) for similar configurations 


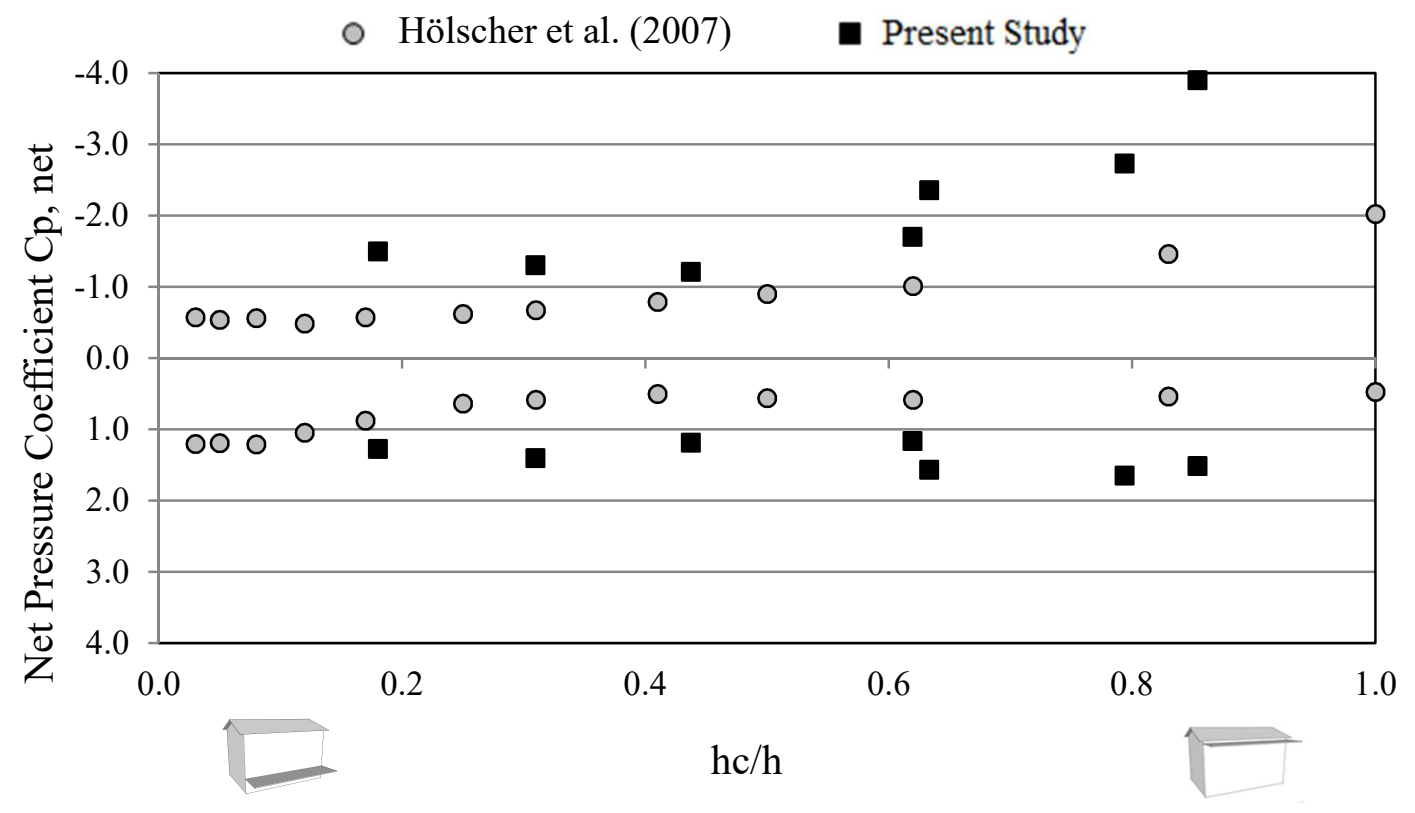

Fig. 21 Comparison between results of the present study and those of Hölscher et al. (2007) for similar configurations for a velocity pressure based on 1-hour wind speed data 

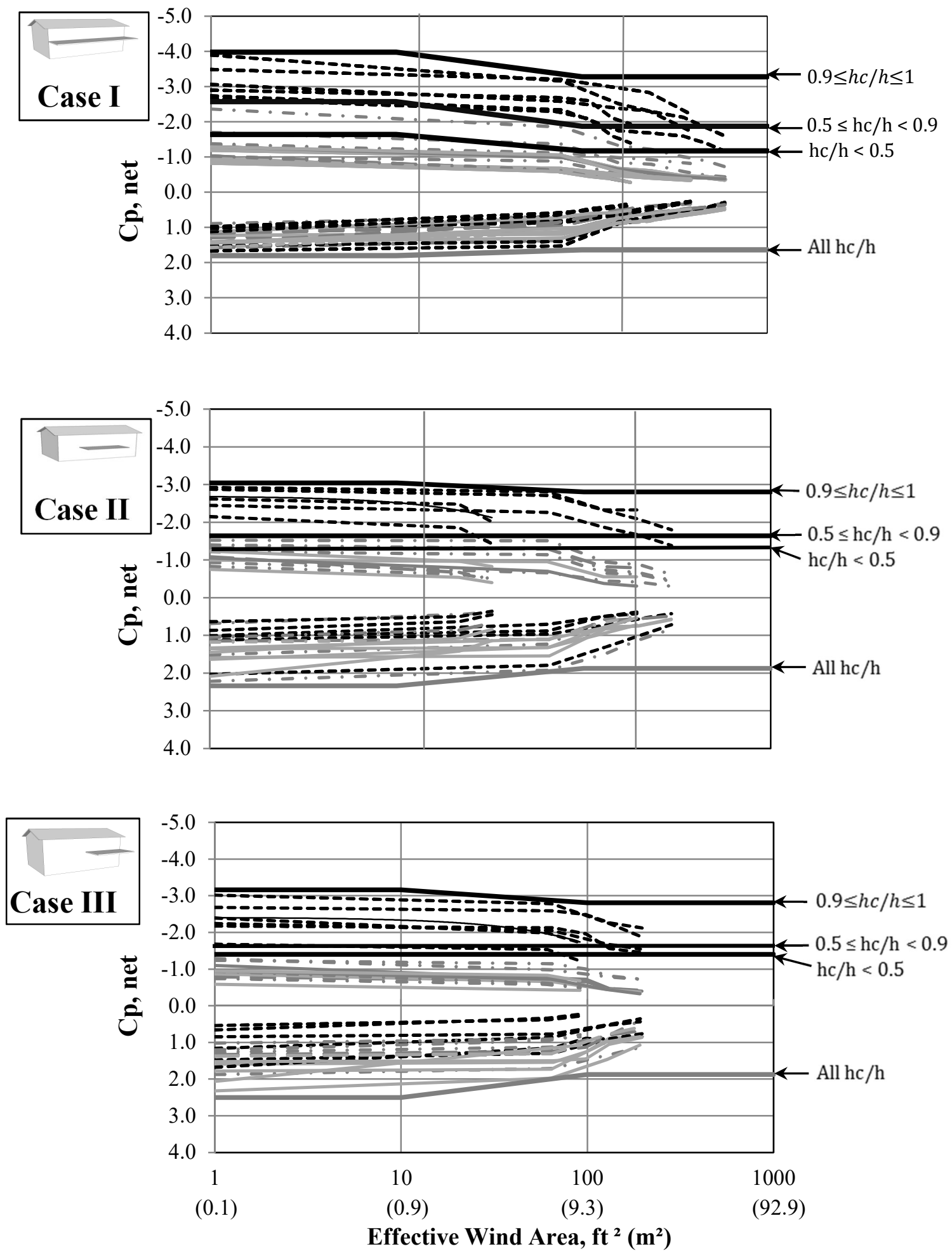

---- Tests with $0.9 \leq h c / h \leq 1 \quad-$ Tests with $0.5 \leq h c / h<0.9 \quad \longrightarrow$ Tests with $h c / h<0.5$

Fig. 22 Area averaging effect for all runs and envelopes for the corresponding ranges 

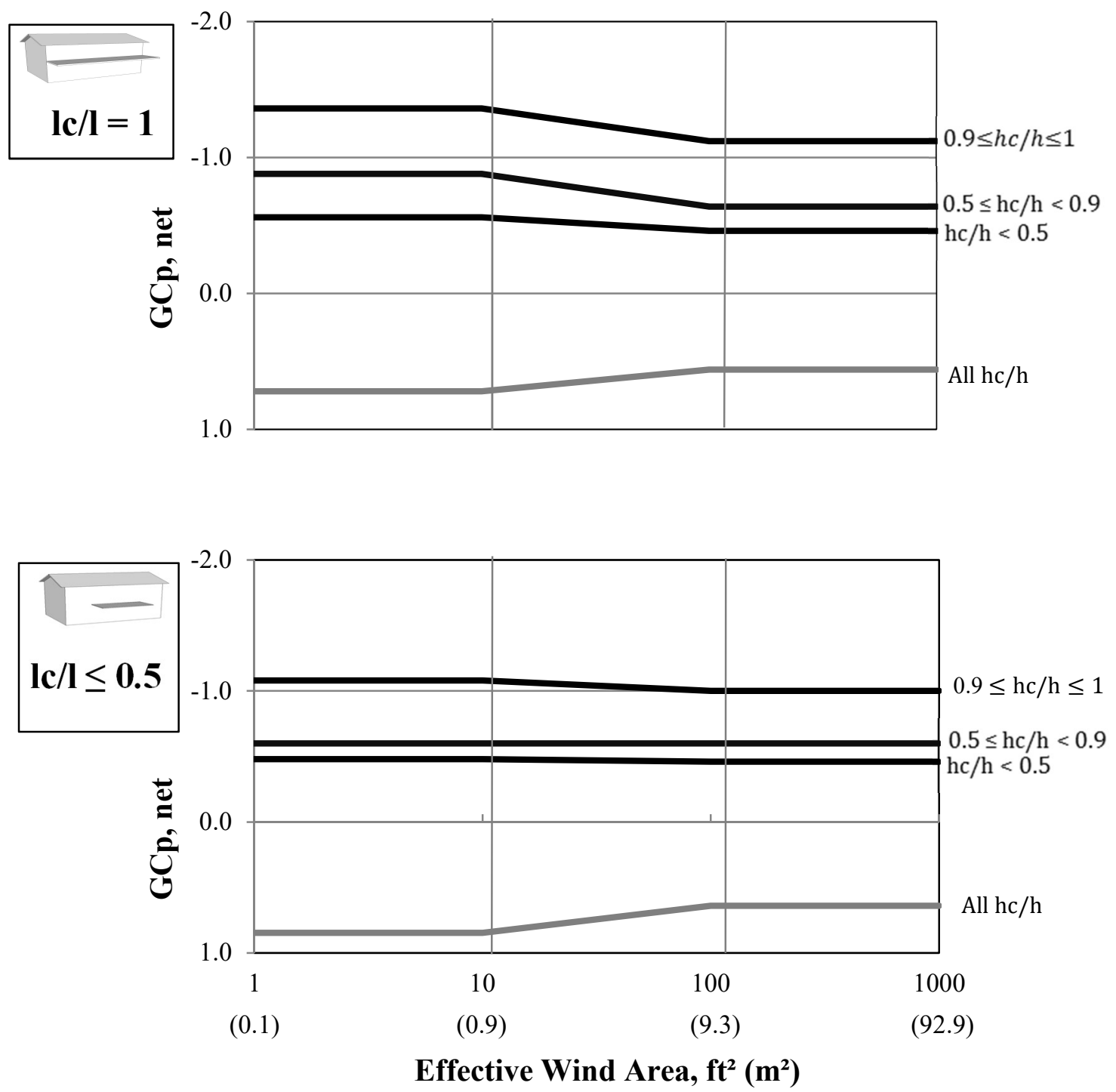

Note: for intermediate lc/l ratios use linear interpolation between the two figures

Fig. 23 Proposed guidelines for $G C p$, net on attached canopies 


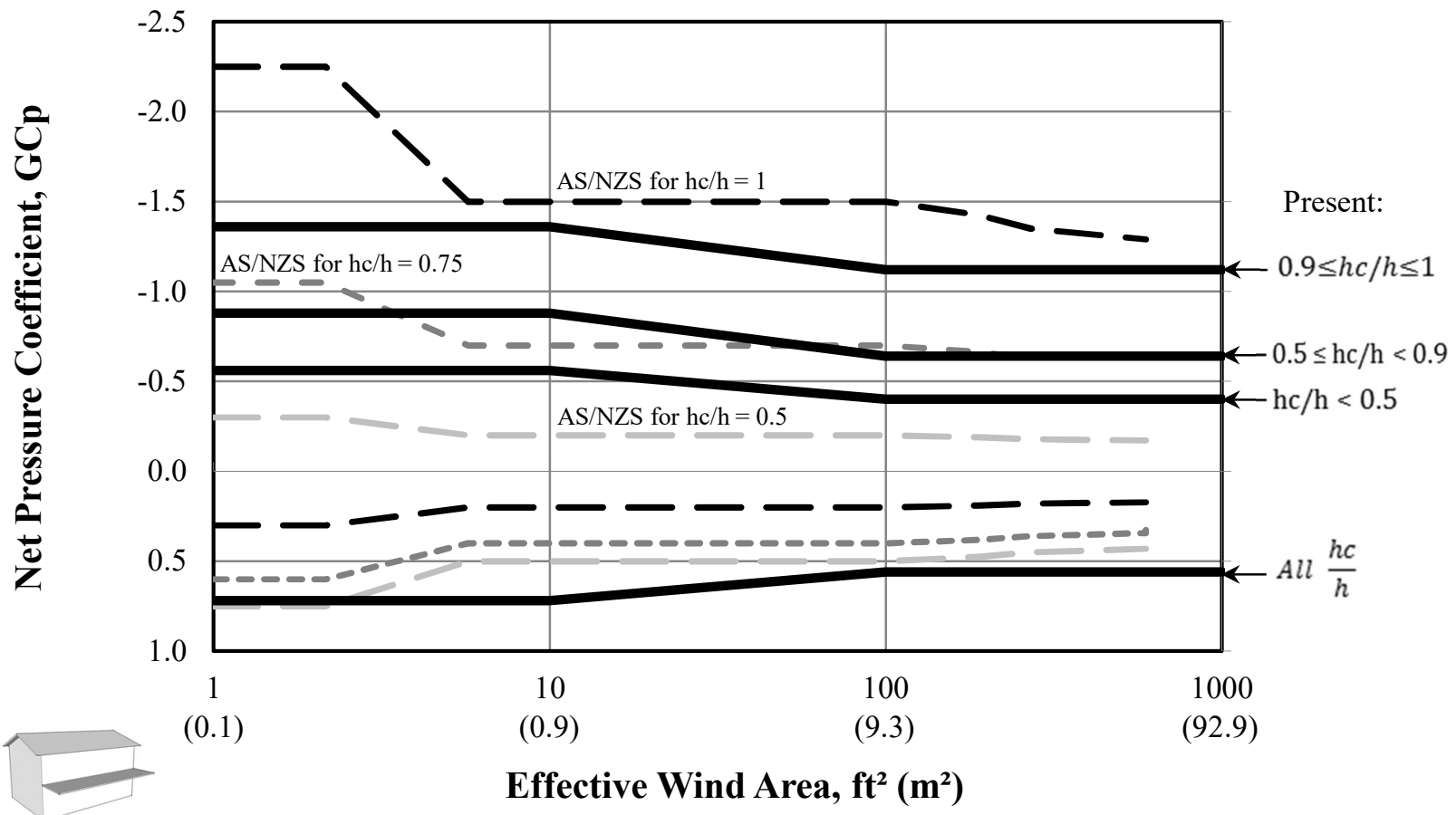

Fig. 24 Comparisons between the recommended envelopes of the present study and AS/NZS provisions 


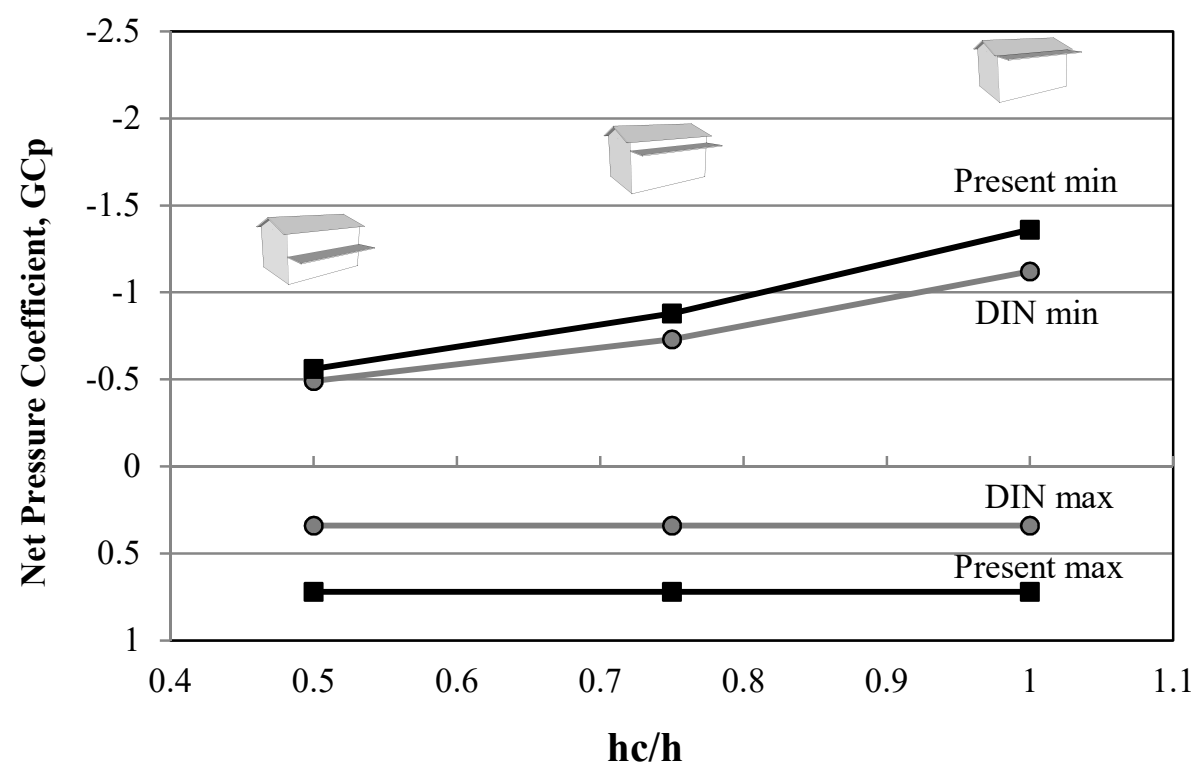

Fig. 25 Comparison between the recommended local net pressure coefficients of the present study and the DIN provisions for three different $\mathrm{hc} / \mathrm{h}$ ratios
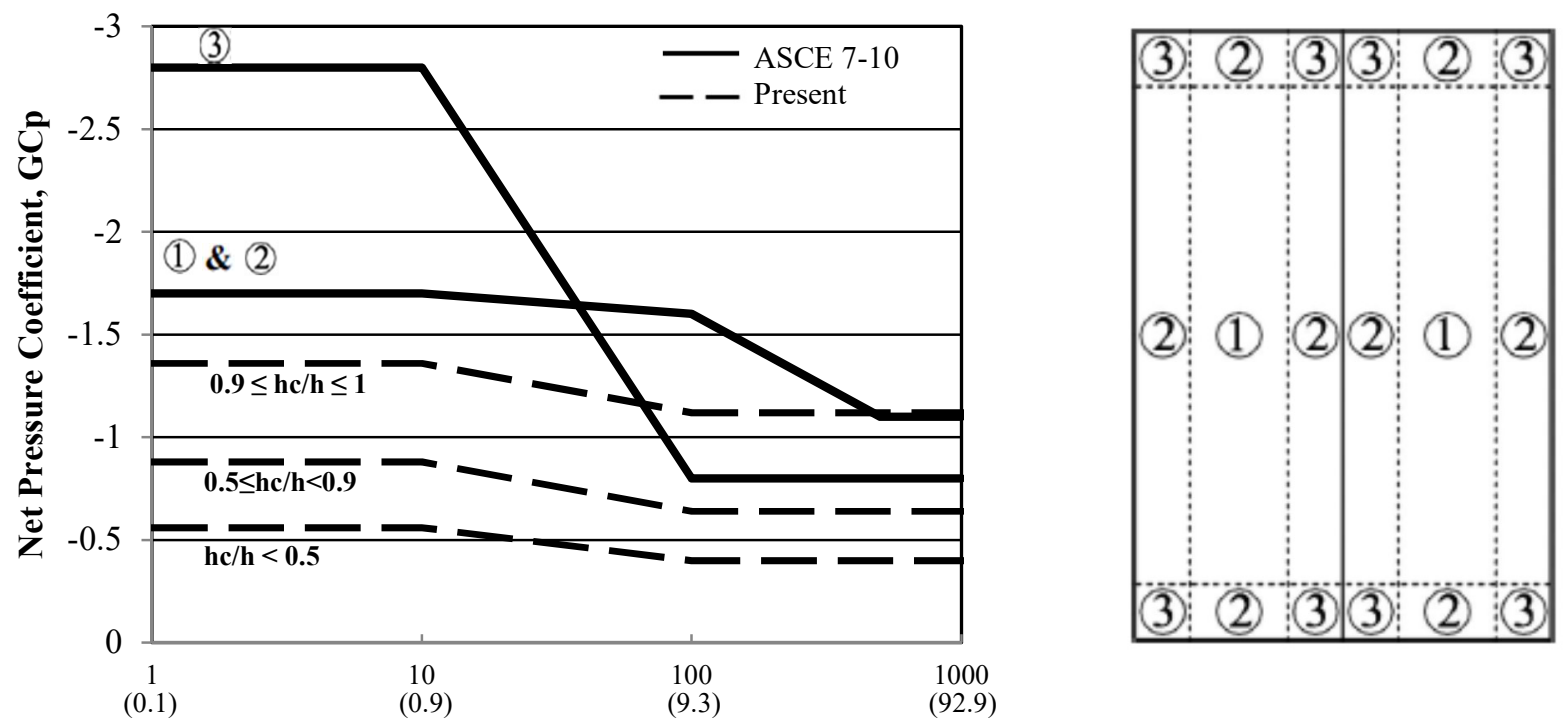

Effective Wind Area, $\mathrm{ft}^{2}\left(\mathrm{~m}^{2}\right)$

Fig. 26 Comparisons between the recommended design values for a full length canopy and ASCE 7-10 provisions for overhangs on gable roof of slope smaller than $7^{\circ}$ (Figure 30.4-2A) 
Table 1. Configurations tested for each of the 3 cases resulting in 63 unique configurations

\begin{tabular}{cccccc}
\hline Run & $\mathrm{h}(\mathrm{cm})$ & $\mathrm{hc}(\mathrm{cm})$ & $\mathrm{wc}(\mathrm{cm})$ & $\mathrm{hc} / \mathrm{h}$ & $\mathrm{hc} / \mathrm{wc}$ \\
\hline$* 1$ & 3.5 & 2.85 & 3.65 & 0.81 & 0.78 \\
2 & 3.5 & 2.85 & 2.38 & 0.81 & 1.2 \\
3 & 3.5 & 2.85 & 1.13 & 0.81 & 2.52 \\
$* 4$ & 7 & 6.35 & 3.65 & 0.91 & 1.74 \\
5 & 7 & 6.35 & 2.38 & 0.91 & 2.67 \\
6 & 7 & 6.35 & 1.13 & 0.91 & 5.62 \\
$* 7$ & 7 & 3.5 & 3.65 & 0.5 & 0.96 \\
8 & 7 & 3.5 & 2.38 & 0.5 & 1.47 \\
9 & 7 & 3.5 & 1.13 & 0.5 & 3.1 \\
10 & 10.3 & 9.65 & 3.65 & 0.94 & 2.64 \\
11 & 10.3 & 9.65 & 2.38 & 0.94 & 4.05 \\
12 & 10.3 & 9.65 & 1.13 & 0.94 & 8.54 \\
13 & 10.3 & 7 & 3.65 & 0.68 & 1.92 \\
14 & 10.3 & 7 & 2.38 & 0.68 & 2.94 \\
15 & 10.3 & 7 & 1.13 & 0.68 & 6.19 \\
16 & 10.3 & 3.5 & 3.65 & 0.34 & 0.96 \\
17 & 10.3 & 3.5 & 2.38 & 0.34 & 1.47 \\
18 & 10.3 & 3.5 & 1.13 & 0.34 & 3.1 \\
19 & 10.3 & 2.1 & 3.65 & 0.2 & 0.58 \\
20 & 10.3 & 2.1 & 2.38 & 0.2 & 0.88 \\
21 & 10.3 & 2.1 & 1.13 & 0.2 & 1.86
\end{tabular}

*Configurations previously tested for Case I (Zisis and Stathopoulos, 2010) 